\title{
Study on Deformation and Permeation Properties of Gas-Containing Fractured Rock
}

\author{
Yushun Yang $\mathbb{D})^{1,2}$ Dongming Zhang $\mathbb{D}^{1,2}$ and Shujian $\mathrm{Li}^{1,2}$ \\ ${ }^{1}$ State Key Laboratory of Coal Mine Disaster Dynamics and Control, Chongqing University, Chongqing 400044, China \\ ${ }^{2}$ College of Resources and Environmental Science, Chongqing University, Chongqing 400044, China
}

Correspondence should be addressed to Dongming Zhang; zhangdm@cqu.edu.cn

Received 18 December 2018; Revised 29 March 2019; Accepted 17 April 2019; Published 25 June 2019

Academic Editor: Andri Stefansson

Copyright (C) 2019 Yushun Yang et al. This is an open access article distributed under the Creative Commons Attribution License, which permits unrestricted use, distribution, and reproduction in any medium, provided the original work is properly cited.

\begin{abstract}
In this paper, we investigated the gas permeation properties of fractured rock during the process of stage load axial stress and cyclic load and unload confining pressure and come to some conclusions as follows: (1) the relationship between radial strain and deviatoric stress satisfied the quadratic polynomial function, and the relationship between permeability and deviatoric stress satisfied the exponential function under different axial stress levels; (2) in the staged load axial stress process, the axial straindeviatoric curves of specimens conform to the quadratic polynomial function. The axial strain-deviatoric curves of specimens conform to linear function when confining pressure is $8.6 \mathrm{MPa}$ or $2.0 \mathrm{MPa}$ at different axial stress levels; (3) we used the permeability damage rate and maximum permeability damage rate to evaluate the recovery degree and reduction extent of permeability; (4) we used the volume expansion ratio and the maximum volume expansion ratio to evaluate the expansion degree and increase extent of rock samples' volume.
\end{abstract}

\section{Introduction}

In the underground mining process, the coal body affected by mining has multiple distributions of stress field, which leads to constant abutment stress or pressure relief area in the mining process, while the roof strata of the goaf are broken and undergo a repeated loading and unloading process. The gas in the coal seam migrates upward and accumulates along the fractured rock mass of the coal seam roof, which easily causes a gas outburst accident [1]. Therefore, it is important to investigate the deformation and permeability of fractured rock.

Many researches have been done for the mechanic properties of coal-rock in recent years. It is considered that confining pressure and pore pressure affect rock permeability in different degrees [2-5], the change of rock permeability can be explained by effective stress principle, and a damage model was proposed based on micromechanics to describe the anisotropic damage characteristics of rock samples [6]. The test results show that the permeability of brittle rock increases rapidly at a critical failure point [7], while the mechanical and permeability characteristics of sandstone and limestone are different before and after failure [8]. Zhao et al. [9] conducted the model of the logical fracture behavior of rock cracks subjected to hydraulic pressure and far field stresses. In view of the creep-seepage coupling characteristics of rock, the variation of seepage velocity with time in the process of complete creep of rock was analyzed [10], the permeability characteristics of clay rock during a triaxial creep process were discussed [11], and the creep, permeability variation, and seepage-creep coupling mechanism of rocks were discussed during the loading and unloading process [12]. According to the cyclic loading and unloading test of rock specimens, the permeability evolution law of sandstone specimens in the whole process of failure was analyzed [13], and the relationship between the damage evolution and permeability of granite specimens is also analyzed [14]. Zhao et al. [15] conducted extensive laboratory investigation of the nonlinear rheological mechanical characteristics of hard rock under cyclic incremental loading and unloading and proposed a data processing algorithm to analyze the experimental data. According to the sandstone specimen test, the 
variation of permeability with axial strain, radial strain, and volumetric strain was analyzed in the process of complete stress-strain curves [16] and established the gas seepage model of a strain index and the effect of stress concentration state on the deformation law and seepage characteristics of sandstone in the process of unloading confining pressure failure $[17,18]$. Huang and $\mathrm{Hu}[19]$ investigated the damage of shale rock impacted by a high-pressure supercritical carbon dioxide $\left(\mathrm{SC}-\mathrm{CO}_{2}\right)$ jet and used a well-designed apparatus to conduct experiments with a high-pressure $\mathrm{SC}-\mathrm{CO}_{2}$ jet impacting shale core plugs. A rough single-fracture sandstone seepage model based on dimensional analysis is established for the fracture seepage test of rough single-fractured sandstone specimens [20]. Huang et al. [21] investigated the lateral jetting commencing points associated with the peak pressure when an arc-curved jet impacts flat, concave, convex, and inclined solid surfaces, respectively. Temperature and water content have different effects on rock permeability. It is considered that the permeability coefficient increases with temperature. For a given temperature level, the transmittance decreases with the increase of confining pressure, and the decline rate decreases gradually [22]. The interaction between physical properties, volume change, and permeability of hard sandstone under complete water saturation is described [23]. Zhao et al. [24] performed the transient pulse tests on single rock fractures at different confining pressures, and a new data analysis method based on polynomial fitting was introduced to investigate the relationship between flow velocity and hydraulic gradient.

Previous studies mainly focused on the mechanics and permeability of intact coal and rock, and there is little research on the deformation and permeability of fractured rock. During the mining process of the working face, the roof rock is deformed and broken, and then, the fractured rock mass is formed. The gas inside the coal seam migrates to the goaf and along the crack to the top of the rock stratum. Therefore, the study of gas migration in fractured rock mass during the loading and unloading process is of great significance for the treatment of coal and gas outbursts.

\section{Specimens, Equipment, and Methods}

Rock samples come from the roof of coal seam \#2+3 of the Yibin coal field in Sichuan, China. Several cuboid rock samples measuring $100 \mathrm{~mm} \times 100 \mathrm{~mm} \times 150 \mathrm{~mm}$ were cut into the appropriate size of $50 \mathrm{~mm}$ diameter and $100 \mathrm{~mm}$ length for triaxial seepage tests. A thermal-fluid-solid coupling triaxial servo seepage device developed (Chongqing University, Chongqing, China) [25] was employed to conduct the triaxial seepage tests, as shown in Figure 1. The equipment can conduct a coal-rock gas permeability test under different stresses and gas pressure. The maximum axial pressure is $200 \mathrm{kN}$, the confining pressure is $10 \mathrm{MPa}$, the maximum axial deformation displacement is $60 \mathrm{~mm}$, and the maximum radial deformation is $6 \mathrm{~mm}$. The temperature ranges from room temperature to $100^{\circ} \mathrm{C}$. The stress measurement system has an accuracy of $\pm 1 \%$, a deformation accuracy of $\pm 1 \%$, and a temperature control accuracy of $\pm 1 \%$.
During the coal seam mining process, the stress changes complexly in front of the working face and appears on the stress concentration zone, the stress reduction zone, and the original stress zone. The overburdened strata in the goaf are broken; the roof falls and undergoes a complex loading and unloading process. Therefore, it is of great significance to study the mechanical and permeability characteristics of fractured rock samples during the loading and unloading process to prevent and control coal and gas outbursts. Load and unload seepage tests on specimens damaged by triaxial compression, that is, loading axial stress at stage and cyclic loading and unloading confining pressure test of fractured rock, are as follows: (1) gradually apply $\sigma_{1}=\sigma_{2}\left(\sigma_{3}\right)$ to a hydrostatic pressure of $2 \mathrm{MPa}$; (2) keep the gas pressure at $0.5 \mathrm{MPa}$; (3) keep the gas fully absorbed for $12 \mathrm{~h}$ until reaching equilibrium; (4) load axial stress of $4 \mathrm{MPa}, 6 \mathrm{MPa}, 8 \mathrm{MPa}$, $10 \mathrm{MPa}, 12 \mathrm{MPa}, 14 \mathrm{MPa}, 16 \mathrm{MPa}, 18 \mathrm{MPa}$, and $20 \mathrm{MPa}$ at the stress control loading rate of $0.05 \mathrm{kN} / \mathrm{s}$ at stage. Under different axial stress stages, load confining pressure of $8.6 \mathrm{MPa}$ at a loading rate of $0.05 \mathrm{MPa} / \mathrm{s}$, then unload confining pressure of 2.0 $\mathrm{MPa}$ at the same rate; (5) maintain $2 \mathrm{MPa}$ confining pressure constant and load axial stress till fractured rock failure at displacement control loading rate of $0.1 \mathrm{~mm} / \mathrm{min}$. There are 3 fractured rock specimens of $\# j_{1}, \# j_{2}$, and $\# j_{3}$ in this seepage test.

\section{Results and Discussion}

Assuming that the gas flow in the fractured rock conforms to Darcy's law, the permeability of fractured rock was continuously calculated by $[18,25]$

$$
k=\frac{2 v \mu L p_{2}}{S\left(p_{1}^{2}-p_{2}^{2}\right)},
$$

where $k$ presents the permeability $(\mathrm{mD}), v$ is gas seepage velocity $\left(\mathrm{cm}^{3} / \mathrm{s}\right), \mu$ refers to the gas kinematic viscosity $(\mathrm{Pa} \cdot \mathrm{s}), L$ is the length of fractured rock $(\mathrm{mm}), S$ is the crosssection area of fractured rock $\left(\mathrm{mm}^{2}\right), p_{1}$ is gas pressure at the sample inlet $(\mathrm{MPa})$, and $p_{2}$ is gas pressure at the sample outlet (MPa).

3.1. Analysis of Deformation and Permeability Properties. The complete stress-strain-permeability curves of fractured rock under load and unload conditions are presented in Figure 2.

We can see from Figure 2 that the permeability of each sample fluctuates greatly; this is because this is related to the test scheme designed in this paper. Specific test schemes are load axial stress of $4 \mathrm{MPa}, 6 \mathrm{MPa}, 8 \mathrm{MPa}, 10 \mathrm{MPa}$, $12 \mathrm{MPa}, 14 \mathrm{MPa}, 16 \mathrm{MPa}, 18 \mathrm{MPa}$, and $20 \mathrm{MPa}$ at a stress control loading rate of $0.05 \mathrm{kN} / \mathrm{s}$ at stage. When the axial pressure is loaded to the preset stress level, constant axial stress and loading-unloading confining pressure tests are carried out. The permeability decreases nonlinearly in the process of loading confining pressure but increases nonlinearly in the process of unloading confining pressure. Therefore, the permeability of the sample shows big fluctuations.

Details are observed in Figure 2, while maintaining confining pressure constant and load axial stress process, the 


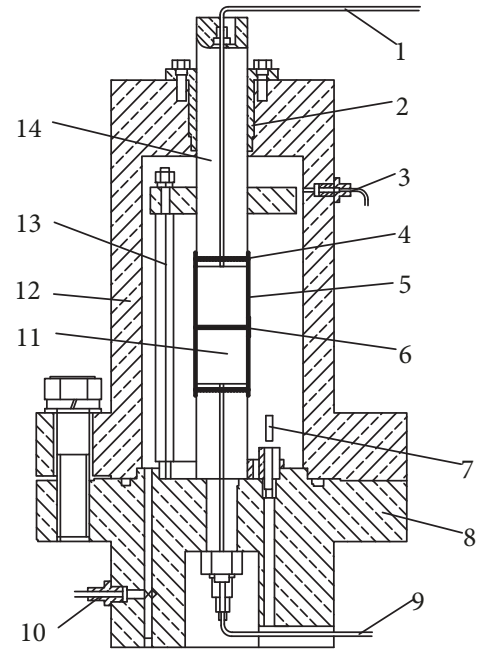

(a)

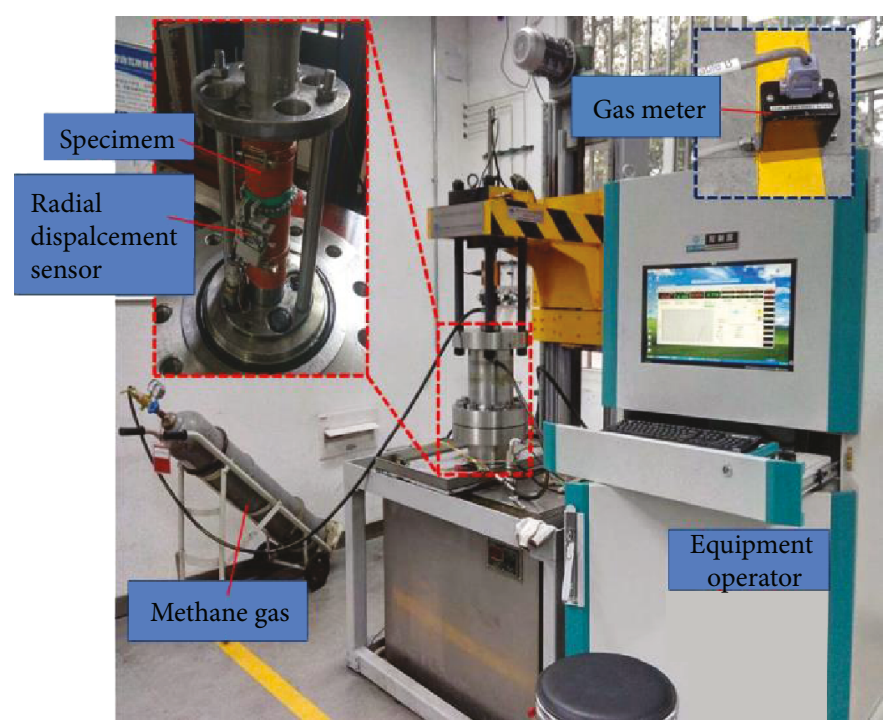

(b)

Figure 1: Thermal-fluid-solid coupling triaxial servo seepage device. 1: intake tube; 2: guide sleeve; 3: row air tube; 4: metal hoop; 5: heat shrinkable tube; 6: radial displacement sensor; 7: sensor junction column; 8: lower seat; 9: outlet pipe; 10: into and out of oil hole; 11: specimen; 12: upper seat; 13: guide device; 14: pressurized piston rod.

fractured rock shows axial compression deformation, radial expansion, and permeability reduction nonlinearly. As the axial stress increases from $2 \mathrm{MPa}$ to $4 \mathrm{MPa}$, the axial strain of specimen $\# j_{1}$ increases by $0.054 \times 10^{-2}$, the radial strain increases by $-0.001 \times 10^{-2}$, and the permeability decreases from $21.206 \mathrm{mD}$ to $19.82 \mathrm{mD}$ : the decrement of permeability was $6.53 \%$; the axial strain of sample $\# j_{2}$ increases by 0.089 $\times 10^{-2}$, the radial strain increases by $-0.001 \times 10^{-2}$, and the permeability decreases from $12.582 \mathrm{mD}$ to $11.499 \mathrm{mD}$ : the decrement of permeability was $8.6 \%$; the axial strain of sample $\# j_{3}$ increases by $0.141 \times 10^{-2}$, the radial strain increases by $-0.003 \times 10^{-2}$, and the permeability decreases from $9.387 \mathrm{mD}$ to $6.303 \mathrm{mD}$ : the decrement was $32.85 \%$.

Subsequently, load axial pressure of $4 \mathrm{MPa}, 6 \mathrm{MPa}$, $8 \mathrm{MPa}, 10 \mathrm{MPa}, 12 \mathrm{MPa}, 14 \mathrm{MPa}, 16 \mathrm{MPa}, 18 \mathrm{MPa}$, and $20 \mathrm{MPa}$ at stage, and load confining pressure at stress control loading rate of $0.05 \mathrm{MPa} / \mathrm{s}$ to $8.6 \mathrm{MPa}$, then unload confining stress to $2.0 \mathrm{MPa}$ at the same rate. The fractured rock shows axial compression deformation, radial shrinkage deformation in the load confining pressure process, while the axial deformation is almost invariable, and radial expansion during unload confining pressure.

(1) The first load and unload confining pressure was under $4 \mathrm{MPa}$ axial stress; as the confining stress increases from $2 \mathrm{MPa}$ to $8.6 \mathrm{MPa}$, the axial strain of the specimen $\# j_{1}$ increment was $7.41 \%$, the radial strain increases to $0.185 \times 10^{-2}$, and the permeability decrement was $58.74 \%$; the axial strain of sample $\#_{2}$ decrement was $47.19 \%$, the radial strain increases to $0.202 \times 10^{-2}$, and the permeability decrement was $83.53 \%$; the axial strain of sample $\#_{3}$ decrement was $55.32 \%$, the radial strain increases to $0.279 \times$
$10^{-2}$, and the permeability decrement was $38.3 \%$. After unloading confining pressure from $8.6 \mathrm{MPa}$ to $2 \mathrm{MPa}$, the axial strain of sample $\# \mathrm{j}_{1}$ decrement was $3.45 \%$, the radial strain decreases to $36.22 \%$, and the permeability increment was $6.79 \%$; the axial strain of sample $\# j_{2}$ increment was $68.09 \%$, the radial strain decreases to $22.77 \%$, and the permeability increment was $157.13 \%$; the axial strain of sample $\#_{3}$ increment was $90.48 \%$, the radial strain decreases to $25.45 \%$, and the permeability increment was $3.45 \%$. We know that after the first load and unload confining pressure, the permeability recovery rate of sample $\# j_{1}$ is $44.06 \%$, the permeability recovery rate of sample $\#_{2}$ is $42.35 \%$, and the permeability recovery rate of sample $\# j_{3}$ is $63.83 \%$. The calculation of permeability recovery rate is as follows: the permeability of specimens is $19.82 \mathrm{mD}$ when confining pressure is $2 \mathrm{MPa}$ and axial pressure is $4 \mathrm{MPa}$ in stages. The permeability of the specimens is $8.732 \mathrm{mD}$ after a cyclic loading and unloading $(2 \mathrm{MPa} \rightarrow 8.6 \mathrm{MPa} \rightarrow 2 \mathrm{MPa})$ confining pressure under constant axial pressure of $4 \mathrm{MPa}$. The permeability recovery rate of the specimen is the permeability under the loading and unloading confining pressure divided by the original permeability

(2) Maintain $2 \mathrm{MPa}$ confining pressure constant and load axial stress from $4 \mathrm{MPa}$ to $6 \mathrm{MPa}$; the axial strain of the sample $\# j_{1}$ increment was $112.5 \%$, the radial strain decrement was $3.39 \%$, and the permeability decrement was $7.94 \%$; the axial strain of specimen $\# j_{2}$ increment was $81.01 \%$, the radial strain decrement was $5.13 \%$, and the permeability increment 
was $2.79 \%$; the axial strain of specimen $\# j_{3}$ increment was $72.5 \%$, the radial strain decrement was $9.62 \%$, and the permeability decrement was $12.32 \%$. Maintain $6 \mathrm{MPa}$ axial pressure constant and second load and unload confining stress; the axial strain of specimen $\# j_{1}$ increment was $7.56 \%$, the radial strain increment was $8.77 \%$, and the permeability recovery rate was $7.94 \%$; the axial strain of the sample $\# j_{2}$ increment was $10.49 \%$, the radial increment was $9.46 \%$, and the permeability recovery rate was $81.08 \%$; the axial strain of the sample $\# j_{3}$ increment was $7.83 \%$, the radial increment was $9.57 \%$, and the permeability recovery rate was $84.6 \%$

(3) Maintain $2 \mathrm{MPa}$ confining pressure constant and load axial stress from $6 \mathrm{MPa}$ to $8 \mathrm{MPa}$; the axial strain of the sample $\# j_{1}$ increment was $62.5 \%$, the radial decrement was $5.65 \%$, and the permeability decrement was $6.11 \%$; the axial strain of specimen $\# j_{2}$ increment was $51.9 \%$, the radial strain decrement was $6.79 \%$, and the permeability increment was $3.33 \%$; the axial strain of specimen $\#_{3}$ increment was $41.26 \%$, the radial strain decrement was $15.05 \%$, and the permeability decrement was $9.09 \%$. Maintain $8 \mathrm{MPa}$ axial pressure constant and third load and unload confining stress; the axial strain of specimen $\# j_{1}$ increment was $9.13 \%$, the radial strain increment was $5.98 \%$, and the permeability recovery rate was $89.13 \%$; the axial strain of the sample $\#_{2}$ increment was $4.58 \%$, the radial strain increment was $5.96 \%$, and the permeability recovery rate was $83.86 \%$; the axial strain of the sample $\# \mathrm{j}_{3}$ increment was $3.49 \%$, the radial strain increment was $8.57 \%$, and the permeability recovery rate was $90.01 \%$

(4) Maintain $2 \mathrm{MPa}$ confining pressure constant and load axial stress from $8 \mathrm{MPa}$ to $10 \mathrm{MPa}$; the axial strain of the sample $\# j_{1}$ increment was $42.29 \%$, the radial decrement was $8.87 \%$, and the permeability was unchanged; the axial strain of specimen $\# \mathrm{j}_{2}$ increment was $34.46 \%$, the radial strain decrement was $8.13 \%$, and the permeability increment was $3.87 \%$; the axial strain of specimen $\# j_{3}$ increment was $32.82 \%$, the radial strain decrement was $23.68 \%$, and the permeability decrement was $5.55 \%$. Maintain $10 \mathrm{MPa}$ axial pressure constant and fourth load and unload confining stress; the axial strain of specimen $\# \mathrm{j}_{1}$ increment was $4.33 \%$, the radial strain increment was $4.43 \%$, and the permeability recovery rate was $92.68 \%$; the axial strain of sample $\#_{2}$ increment was $2.94 \%$, the radial strain increment was $4.08 \%$, and the permeability recovery rate was $85.19 \%$; the axial strain of the sample $\# j_{3}$ increment was $2.31 \%$, the radial strain increment was $10.34 \%$, and the permeability recovery rate was $94.12 \%$

(5) Maintain $2 \mathrm{MPa}$ confining pressure constant and load axial stress from $10 \mathrm{MPa}$ to $12 \mathrm{MPa}$; the axial strain of the sample $\# j_{1}$ increment was $25.22 \%$, the radial strain decrement was $13.56 \%$, and the permeability increment was $7.89 \%$; the axial strain of specimen $\# j_{2}$ increment was $22 \%$, the radial strain decrement was $8.5 \%$, and the permeability was unchanged; the axial strain of specimen $\# j_{3}$ increment was $23.93 \%$, the radial strain decrement was $41.25 \%$, and the permeability decrement was $6.24 \%$. Maintain $12 \mathrm{MPa}$ axial pressure constant and fifth load and unload confining stress; the axial strain of specimen $\# j_{1}$ increment was $2.61 \%$, the radial strain increment was $2.94 \%$, and the permeability recovery rate was $90.23 \%$; the axial strain of sample $\# j_{2}$ increment was $2.34 \%$, the radial strain increment was $3.57 \%$, and the permeability recovery rate was $86.95 \%$; the axial strain of sample $\# \mathrm{j}_{3}$ increment was $1.82 \%$, the radial strain increment was $13.83 \%$, and the permeability recovery rate was $93.34 \%$

(6) Maintain $2 \mathrm{MPa}$ confining pressure constant and load axial stress from $12 \mathrm{MPa}$ to $14 \mathrm{MPa}$; the axial strain of the sample $\# j_{1}$ increment was $20.55 \%$, the radial strain decrement was $21.91 \%$, and the permeability increment was $10.83 \%$; the axial strain of specimen $\# j_{2}$ increment was $18.08 \%$, the radial strain decrement was $10.35 \%$, and the permeability was unchanged; the axial strain of specimen $\# \mathrm{j}_{3}$ increment was $23.36 \%$, the radial strain decrement was $82.24 \%$, and the permeability decrement was $7.19 \%$. Maintain $14 \mathrm{MPa}$ axial pressure constant and sixth load and unload confining stress; the axial strain of specimen $\# \mathrm{j}_{1}$ increment was $3.07 \%$, the radial strain increment was $4.88 \%$, and the permeability recovery rate was $90.23 \%$; the axial strain of the sample $\# j_{2}$ increment was $1.36 \%$, the radial strain increment was $3.08 \%$, and the permeability recovery rate was $89.99 \%$; the axial strain of the sample $\# j_{3}$ increment was $1.75 \%$, the radial strain increment was $78.95 \%$, and the permeability recovery rate was $92.31 \%$

(7) Maintain $2 \mathrm{MPa}$ confining pressure constant and load axial stress from $14 \mathrm{MPa}$ to $16 \mathrm{MPa}$, the axial strain of the sample $\# j_{1}$ increment was $16.17 \%$, the radial decrement was $64.88 \%$, and the permeability increment was $13.5 \%$; the axial strain of specimen $\# \mathrm{j}_{2}$ increment was $14.34 \%$, the radial strain decrement was $11.19 \%$, and the permeability decrement was $11.09 \%$; the axial strain of specimen $\#_{3}$ increment was $20.98 \%$, the radial strain decreases to $0.083 \times 10^{-2}$, and the permeability was unchanged. Maintain $16 \mathrm{MPa}$ axial pressure constant and seventh load and unload confining pressure; the axial strain of specimen $\# j_{1}$ increment was $2.56 \%$, the radial strain increment was $5.36 \%$, and the permeability recovery rate was $92.85 \%$; the axial strain of specimen $\# j_{2}$ increment was $1.34 \%$, the radial strain increment was $2.52 \%$, and the permeability recovery rate was 93.72\%; the axial strain of the sample $\# j_{3}$ increment was $2.38 \%$, the radial strain increment was $16.87 \%$, and the permeability recovery rate was $91.67 \%$ 
(8) Maintain $2 \mathrm{MPa}$ confining pressure constant and load axial stress from $16 \mathrm{MPa}$ to $18 \mathrm{MPa}$; the axial strain of the sample $\# j_{1}$ increment was $14.51 \%$, the radial strain decrement was $77.97 \%$, and the permeability increment was $7.7 \%$; the axial strain of specimen $\#_{2} j_{2}$ increment was $11.72 \%$, the radial strain decrement was $11.48 \%$, and the permeability decrement was $13.31 \%$; the axial strain of specimen $\# j_{3}$ increment was $21.05 \%$, the radial strain decreases to $-0.239 \times 10^{-2}$, and the permeability was unchanged. Maintain $18 \mathrm{MPa}$ axial pressure constant and eighth load and unload confining stress; the axial strain of specimen $\# j_{1}$ increment was $1.63 \%$, the radial strain increment was $30.77 \%$, and the permeability recovery rate was $90.48 \%$; the axial strain of the sample $\# j_{2}$ increment was $1.62 \%$, the radial increment was $2.78 \%$, and the permeability recovery rate was $84.59 \%$; the axial strain of the sample $\# \mathrm{j}_{3}$ increment was $1.63 \%$, the radial strain increment was $6.7 \%$, and the permeability recovery rate was $90.92 \%$

(9) Maintain $2 \mathrm{MPa}$ confining pressure constant and load axial stress from $18 \mathrm{MPa}$ to $20 \mathrm{MPa}$; the axial strain of the sample $\# j_{1}$ increment was $16.35 \%$, the radial strain decreases to $-0.069 \times 10^{-2}$, and the permeability increment was $7.9 \%$; the axial strain of specimen $\# \mathrm{j}_{2}$ increment was $10.61 \%$, the radial strain decrement was $15.32 \%$, and the permeability decrement was $9.07 \%$; the axial strain of specimen $\# j_{3}$ increment was $25.14 \%$, the radial strain decreases to $-0.516 \times 10^{-2}$, and the permeability decrement was 9.99\%. Maintain $20 \mathrm{MPa}$ axial stress constant and ninth load and unload confining stress; the axial strain of specimen $\# j_{1}$ increment was $3.69 \%$, the radial strain increment was $13.04 \%$, and the permeability recovery rate was $92.68 \%$; the axial strain of the sample $\# \mathrm{j}_{2}$ increment was $1.71 \%$, the radial increment was $3.19 \%$, and the permeability recovery rate was $90.02 \%$; the axial strain of the sample $\# j_{3}$ increment was $1.89 \%$, the radial strain increment was $1.94 \%$, and the permeability recovery rate was $90.92 \%$

Subsequently, maintain $2 \mathrm{MPa}$ confining pressure constant and increase axial stress until the fractured rock failure; the ultimate strength of specimen $\#_{1}$ is $22.15 \mathrm{MPa}$, the ultimate bearing capacity of sample $\# j_{1}$ was $22.15 \mathrm{MPa}$, and the corresponding values of axial strain, radial strain, and permeability were $1.711 \times 10^{-2},-0.962 \times 10^{-2}$, and $5.683 \mathrm{mD}$, respectively; the ultimate bearing capacity of sample $\# j_{2}$ was $31.94 \mathrm{MPa}$ and the corresponding values for axial strain, radial strain, and permeability were $1.563 \times 10^{-2},-0.693 \times$ $10^{-2}$, and $0.676 \mathrm{mD}$, respectively; the ultimate bearing capacity of sample $\# j_{3}$ was $22 \mathrm{MPa}$ and the corresponding values for axial strain, radial strain, and permeability were $2.4 \times$ $10^{-2},-2.37 \times 10^{-2}$, and $1.475 \mathrm{mD}$, respectively. In summary, it can be seen that in maintain $2 \mathrm{MPa}$ confining stress and the load axial stress process, the pores and cracks of the sample are slowly closed and compacted; the specimen shows axial compression deformation and radial expansion. As the axial pressure level increases, the axial strain increases slowly, and its increment decreases gradually; the radial strain increases slowly and increases negatively, and its decrement increases gradually; the permeability of samples $\# j_{1}$ and $\# j_{3}$ from gradually decreasing increases; the permeability of sample $\# j_{2}$ is the opposite. Because of the anisotropy of the fractured rock and the existence of cracks in the sample, the permeability variation trend is different under different stress states.

During the process constant confining pressure and load axial stress from $8 \mathrm{MPa}$ to $10 \mathrm{MPa}$, the permeability of sample $j_{1}$ was unchanged; this is because the specimen itself is the specimen after triaxial compression failure; it is a fractured rock sample. Then, the permeation characteristic tests of step-by-step axial compression and cyclic loading and unloading confining pressure were carried out. Perhaps, it is the internal pores and cracks of specimens that have been closed after loading to the $8 \mathrm{MPa}$ level under axial pressure. At this time, constant axial pressure and cyclic loading-unloading confining pressure tests are carried out, which makes the internal pores and cracks of the specimen close further during the loading confining pressure process, while the unloading confining pressure fails to make the internal voids and cracks open effectively, resulting in no change in the permeability of specimen $j_{1}$ during the next stage of the loading confining pressure process, while the permeability of samples $j_{2}$ and $\mathrm{j}_{3}$ changes. The sample itself is heterogeneous anisotropy, which results in the greater dispersion of the test results. The smaller loading range of the axial compression during the stage loading process is also one of the reasons for the unchanged permeability of sample $\mathrm{j}_{1}$.

During the load confining stress process, the pores and cracks of the specimen are gradually compacted, and the specimen shows the axial compression deformation and radial compression, leading to reducing the difficulty of passage through the specimen; the permeability gradually decreased. But during the unload confining pressure process, the pores and cracks of the sample gradually open, and the sample shows the axial compression deformation and radial compression, leading to increasing the difficulty of passage through the specimen; the permeability of the specimen increases nonlinearly.The deviatoric stress-strainpermeability curves of specimens did not coincide during the load and unload confining pressure process, and the samples were damaged in a certain degree; therefore, the permeability cannot be restored to the permeability value at loading time, and the permeability recovery degree of samples was different under different axial stress states.

The axial strain, radial strain, and permeability of samples under different stresses are shown in Table 1.

Based on the test results in Table 1, strain-deviatoric stress-permeability curves of sample $\# j_{1}$ at different axial stress levels were plotted as shown in Figure 3. Only sample $\# j_{1}$ was analyzed below.

The volumetric strain-deviatoric stress-permeability curves of specimen $\# j_{1}$ under different stress states are shown in Figure 3(a). We can see that in maintain confining pressure constant and staged load axial stress process, the volumetric strain increases gradually with the increase of 


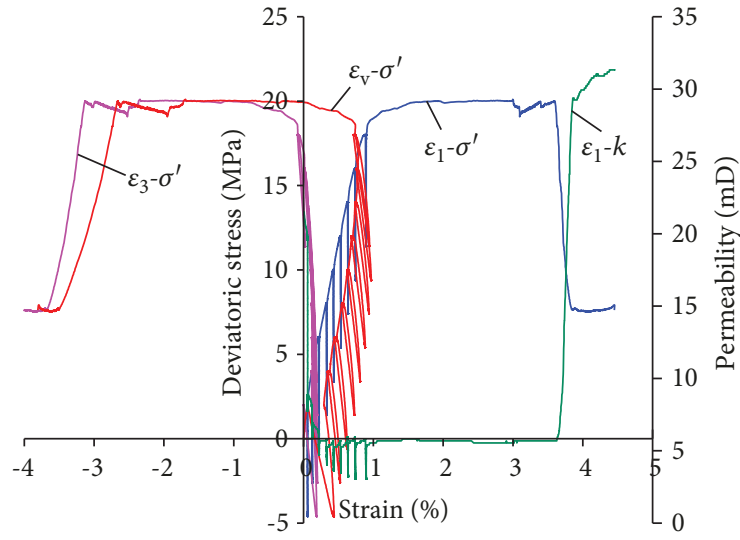

(a) Sample \#j

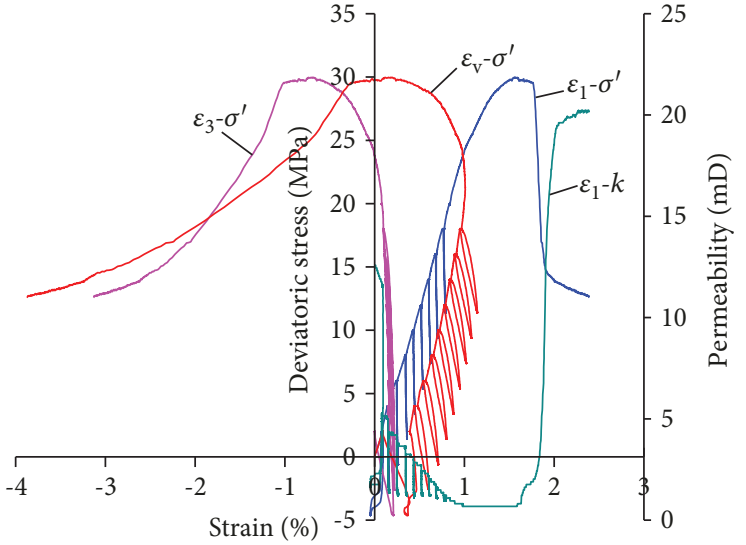

(b) Sample $\# j_{2}$

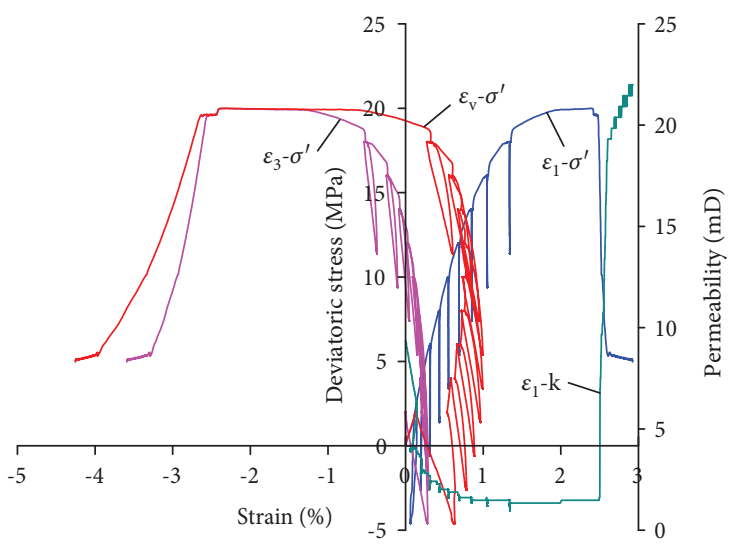

(c) Sample \# $j_{3}$

FIGURE 2: Complete stress-strain-permeability curves of fractured rock.

deviatoric stress, and the permeability was the opposite. But in maintain axial stress constant and unload confining stress process, the volumetric strain of specimens decreases gradually, and permeability was the opposite.

Maintain $2 \mathrm{MPa}$ confining pressure constant and load axial stress $2 \mathrm{MPa} \rightarrow 4 \mathrm{MPa} \rightarrow \cdots 20 \mathrm{MPa}$ till the ultimate strength; the strain-deviatoric stress-permeability curves are shown in Figure 3(b). It can be seen that the specimen shows axial compression deformation, radial shrinkage first and then expansion deformation; the axial strain increases gradually, radial strain increases first and then decreases to zero and increases in the negative direction. The relationship of axial strain-deviatoric stress and radial strain-deviatoric stress was subject to the quadratic polynomial function. As the deviatoric stress increases, the permeability decreases nonlinearly, and the decrease amplitude is about $59.44 \%$ when the deviatoric stress increases from $2 \mathrm{MPa}$ to $4 \mathrm{MPa}$, then the decrease amplitude of the permeability decreases slowly and tends to be stable; fitting permeability and deviatoric stress satisfy the exponential function relationship.

Maintain $8.6 \mathrm{MPa}$ confining pressure constant; axial stress is $4 \mathrm{MPa}, 6 \mathrm{MPa}, \ldots, 20 \mathrm{MPa}$, respectively; the strain-deviatoric stress-permeability curves are shown in Figure 3(c). We know that the specimen shows axial compression deformation, radial shrinkage first and then expansion deformation. The axial strain increases gradually; fit axial strain and deviatoric stress conform to linear function. The radial strain first increases and then decreases; the maximum radial strain is obtained when the deviatoric stress is $-0.6 \mathrm{MPa}$; the fitting results show that the radial strain and deviatoric stress conform to the quadratic polynomial function. The permeability of the sample decreases nonlinearly, and the slope of permeability-deviatoric stress coincides with exponential function.

When the axial pressure level is $4 \mathrm{MPa}, 8 \mathrm{MPa}, \ldots$, $20 \mathrm{MPa}$, etc., confining stress decreases from 8.6 MPa to $2 \mathrm{MPa}$; the deviatoric stress-permeability curves are shown in Figure 3(d). We know that there is axial compression deformation, radial compression first and then expansion. The axial strain increases gradually, and fit axial strain and deviatoric stress are in a linear relationship. The radial strain first increases and then decreases, the radial strain reaches the maximum value when the deviatoric stress is $6 \mathrm{MPa}$, and then, the radial strain of the sample gradually decreases to zero and increases in the negative direction; fitting radial strain and deviatoric stress are in quadratic polynomial relationship. The permeability of the sample decreases nonlinearly as the deviatoric stress increases; when the deviatoric stress is $14 \mathrm{MPa}$, the internal crack of the sample opens and the permeability of sample begins to increase; fitting 
TABLE 1: The axial strain, radial strain, and permeability of each sample under different stresses.

\begin{tabular}{|c|c|c|c|c|c|c|c|c|c|c|}
\hline$\sigma_{1}(\mathrm{MPa})$ & $\sigma_{3}(\mathrm{MPa})$ & $\varepsilon_{1}(\%)$ & $\begin{array}{c}\text { Sample \#j } j_{1} \\
\varepsilon_{3}(\%)\end{array}$ & $k(\mathrm{mD})$ & $\varepsilon_{1}(\%)$ & $\begin{array}{c}\text { Sample \# } \mathrm{j}_{2} \\
\varepsilon_{3}(\%)\end{array}$ & $k(\mathrm{mD})$ & $\varepsilon_{1}(\%)$ & $\begin{array}{c}\text { Sample } \# \mathrm{j}_{3} \\
\varepsilon_{3}(\%)\end{array}$ & $k(\mathrm{mD})$ \\
\hline 2 & 2 & - & - & 21.206 & - & - & 12.582 & - & - & 9.387 \\
\hline 4 & 2 & 0.054 & -0.001 & 19.82 & 0.089 & -0.001 & 11.499 & 0.141 & -0.003 & 6.303 \\
\hline 4 & 8.6 & 0.058 & 0.185 & 8.177 & 0.047 & 0.202 & 1.894 & 0.063 & 0.279 & 3.889 \\
\hline 4 & 2 & 0.056 & 0.118 & 8.732 & 0.079 & 0.156 & 4.870 & 0.120 & 0.208 & 4.023 \\
\hline 6 & 2 & 0.119 & 0.114 & 8.039 & 0.143 & 0.148 & 5.006 & 0.207 & 0.188 & 3.487 \\
\hline 6 & 8.6 & 0.128 & 0.197 & 6.098 & 0.163 & 0.220 & 1.353 & 0.195 & 0.293 & 2.816 \\
\hline 6 & 2 & 0.128 & 0.124 & 6.791 & 0.158 & 0.162 & 4.059 & 0.223 & 0.206 & 2.950 \\
\hline 8 & 2 & 0.208 & 0.117 & 6.376 & 0.240 & 0.151 & 4.194 & 0.315 & 0.175 & 2.682 \\
\hline 8 & 8.6 & 0.224 & 0.199 & 4.851 & 0.262 & 0.223 & 1.353 & 0.314 & 0.286 & 2.280 \\
\hline 8 & 2 & 0.227 & 0.124 & 5.683 & 0.251 & 0.160 & 3.517 & 0.326 & 0.190 & 2.414 \\
\hline 10 & 2 & 0.323 & 0.113 & 5.683 & 0.340 & 0.147 & 3.653 & 0.433 & 0.145 & 2.280 \\
\hline 10 & 8.6 & 0.335 & 0.197 & 4.019 & 0.221 & 0.221 & 1.218 & 0.437 & 0.264 & 1.878 \\
\hline 10 & 2 & 0.337 & 0.118 & 5.267 & 0.350 & 0.153 & 3.112 & 0.443 & 0.160 & 2.146 \\
\hline 12 & 2 & 0.422 & 0.102 & 5.683 & 0.427 & 0.140 & 3.112 & 0.549 & 0.094 & 2.012 \\
\hline 12 & 8.6 & 0.435 & 0.189 & 3.742 & 0.448 & 0.216 & 1.218 & 0.555 & 0.218 & 1.609 \\
\hline 12 & 2 & 0.433 & 0.105 & 5.128 & 0.437 & 0.145 & 2.706 & 0.559 & 0.107 & 1.878 \\
\hline 14 & 2 & 0.522 & 0.082 & 5.683 & 0.516 & 0.130 & 2.706 & 0.684 & 0.019 & 1.743 \\
\hline 14 & 8.6 & 0.537 & 0.173 & 3.604 & 0.538 & 0.207 & 1.218 & 0.692 & 0.150 & 1.475 \\
\hline 14 & 2 & 0.538 & 0.086 & 5.128 & 0.523 & 0.134 & 2.435 & 0.696 & 0.034 & 1.609 \\
\hline 16 & 2 & 0.625 & 0.056 & 5.821 & 0.598 & 0.119 & 2.165 & 0.842 & -0.083 & 1.609 \\
\hline 16 & 8.6 & 0.641 & 0.149 & 3.326 & 0.622 & 0.198 & 1.218 & 0.854 & 0.047 & 1.341 \\
\hline 16 & 2 & 0.641 & 0.059 & 5.405 & 0.606 & 0.122 & 2.029 & 0.860 & -0.069 & 1.475 \\
\hline 18 & 2 & 0.734 & 0.013 & 5.821 & 0.677 & 0.108 & 1.759 & 1.041 & -0.239 & 1.475 \\
\hline 18 & 8.6 & 0.744 & 0.110 & 3.188 & 0.701 & 0.188 & 1.082 & 1.053 & -0.104 & 1.207 \\
\hline 18 & 2 & 0.746 & 0.017 & 5.267 & 0.688 & 0.111 & 1.488 & 1.058 & -0.223 & 1.341 \\
\hline 20 & 2 & 0.868 & -0.069 & 5.683 & 0.761 & 0.094 & 1.353 & 1.324 & -0.516 & 1.475 \\
\hline 20 & 8.6 & 0.898 & 0.023 & 3.049 & 0.790 & 0.176 & 0.947 & 1.343 & -0.370 & 1.207 \\
\hline 20 & 2 & 0.900 & -0.078 & 5.267 & 0.774 & 0.097 & 1.218 & 1.349 & -0.506 & 1.341 \\
\hline $22 / 22.15$ & 2 & 1.711 & -0.906 & 5.683 & 0.840 & 0.078 & 1.082 & 2.400 & -2.370 & 1.475 \\
\hline 24 & 2 & & & & 0.906 & 0.050 & 0.812 & & & \\
\hline 26 & 2 & & & & 0.996 & -0.009 & 0.676 & & & \\
\hline 28 & 2 & & & & 1.119 & -0.122 & 0.676 & & & \\
\hline 30 & 2 & & & & 1.261 & -0.270 & 0.676 & & & \\
\hline 31.94 & 2 & & & & 1.563 & -0.693 & 0.676 & & & \\
\hline
\end{tabular}

permeability and the deviatoric stress are in accordance with the exponential function.

Based on the test results in Table 1, the strain-deviatoric stress-permeability curves of sample $\# j_{2}$ and sample $\# j_{3}$ at different stress levels were plotted as shown in Figures 4 and 5. It can be seen that under different stress levels, the relationship between radial strain and deviatoric stress satisfies the quadratic polynomial function, and the relationship between permeability and deviatoric stress satisfies the exponential function. When the axial pressure is loaded from $2 \mathrm{MPa}$ to $4 \mathrm{MPa}, 6 \mathrm{MPa}, \ldots, 20 \mathrm{MPa}$ until the ultimate strength, the axial strain and deviatoric stress satisfy the quadratic polynomial relationship. When the axial stress is
$4 \mathrm{MPa}, 8 \mathrm{MPa}, \ldots, 20 \mathrm{MPa}$, the confining stress is $8.6 \mathrm{MPa}$ or $2.0 \mathrm{MPa}$; the axial strain-deviatoric stress curves satisfy the linear function relationship.

3.2. Damage Rate of Permeability of Fractured Rock. During the load and unload confining pressure process, the deviatoric stress-permeability curves were not coincident, and the permeability of specimen in the load confining pressure process is higher than the unload confining pressure process. That is, the permeability of the sample was damaged to a certain extent. According to the research results, we used the damage rate of permeability to evaluate the recovery degree of fractured rock permeability, and we used the 


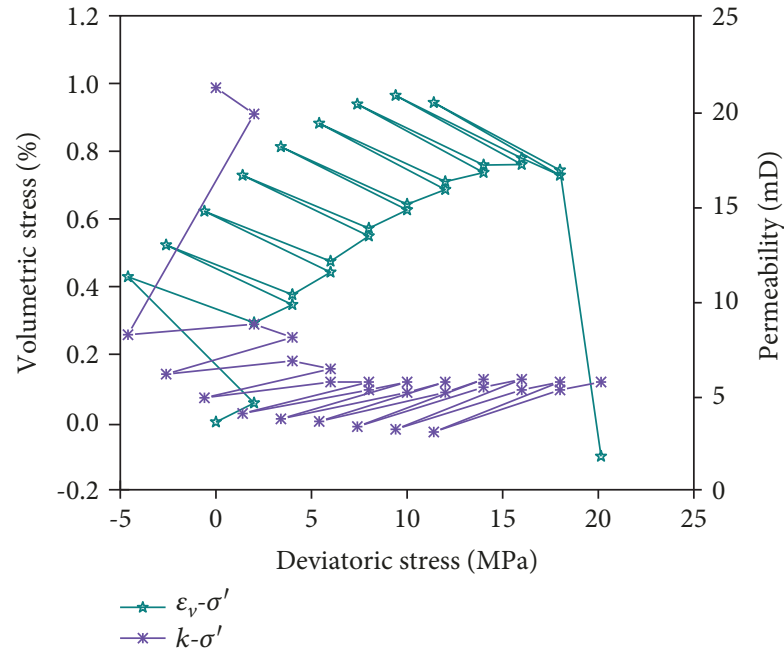

(a)

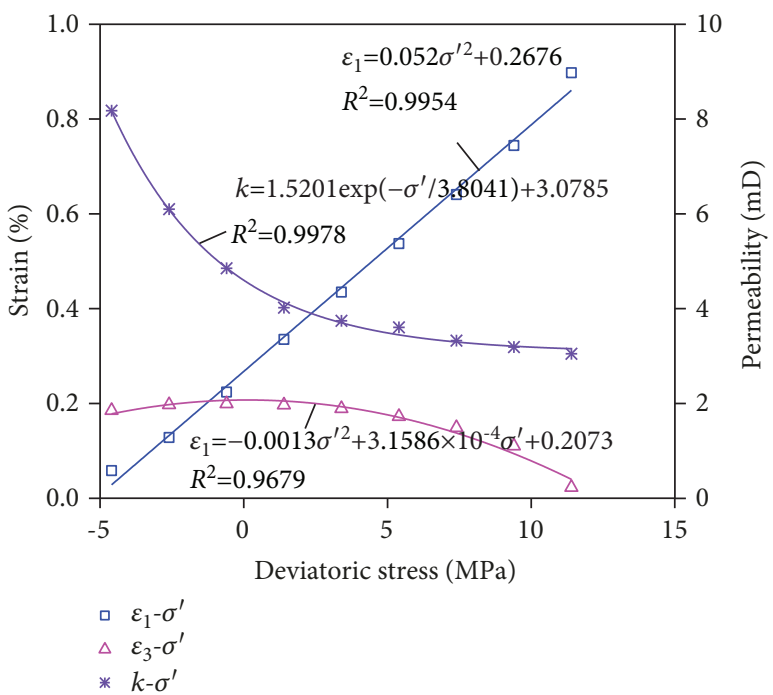

(c)

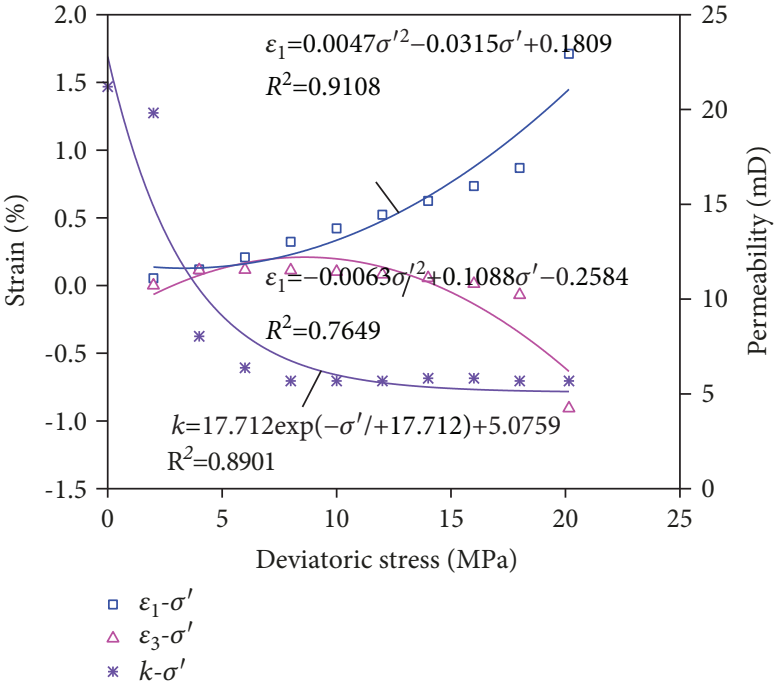

(b)

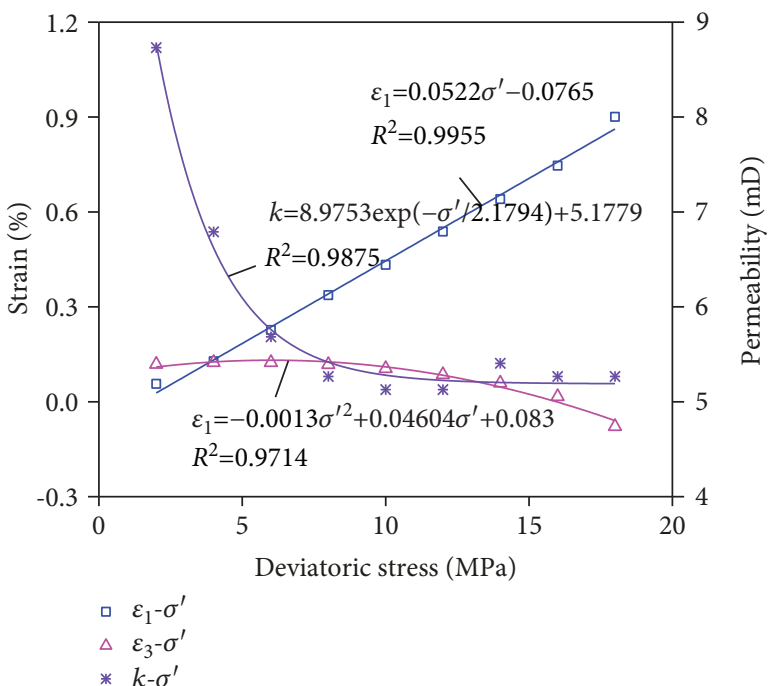

(d)

FIgURE 3: Strain-deviatoric stress-permeability curves of sample $\# j_{1}$ at different stress levels. (a) Volumetric strain-deviatoric stresspermeability curves; (b) maintain $2 \mathrm{MPa}$ confining pressure, load axial stress ( $2 \mathrm{MPa} \rightarrow 4 \mathrm{MPa} \rightarrow \cdots 20 \mathrm{MPa}$ ) at stage; (c) maintain $8.6 \mathrm{MPa}$ confining pressure, axial stress is $4 \mathrm{MPa}, 6 \mathrm{MPa}, \ldots, 20 \mathrm{MPa}$, respectively; (d) axial stress levels of $4 \mathrm{MPa}, 6 \mathrm{MPa}, \ldots, 20 \mathrm{MPa}$, respectively, unload confining pressure to $2 \mathrm{MPa}$.

maximum permeability damage rate to evaluate the reduction amplitude of fractured rock permeability [26, 27]. When the permeability damage rate is larger, the recovery degree of permeability is worse; when the maximum permeability damage rate is larger, the reduction amplitude of permeability is greater. The greater the permeability damage rate is, the worse the recovery degree of permeability will be; the greater the maximum permeability damage rate is, the greater the decrease amplitude of permeability will be.

The permeability damage rate $d_{k}$ can be calculated according to formula (2), and the maximum permeability damage rate $d_{\max }$ can be calculated according to formula (3):

$$
\begin{gathered}
d_{k}=\frac{k_{0}-k_{1}}{k_{0}} \times 100 \%, \\
d_{\max }=\frac{k_{0}-k_{\min }}{k_{0}} \times 100 \%,
\end{gathered}
$$

where $k_{1}$ is fractured rock permeability at the last stress point of unload confining pressure, $k_{0}$ is fractured rock permeability at the first stress point of load confining pressure, and $k_{\min }$ is the fractured rock permeability at the maximum stress point.

According to formulas (2) and (3), in the process of load and unload confining pressure, the permeability damage 


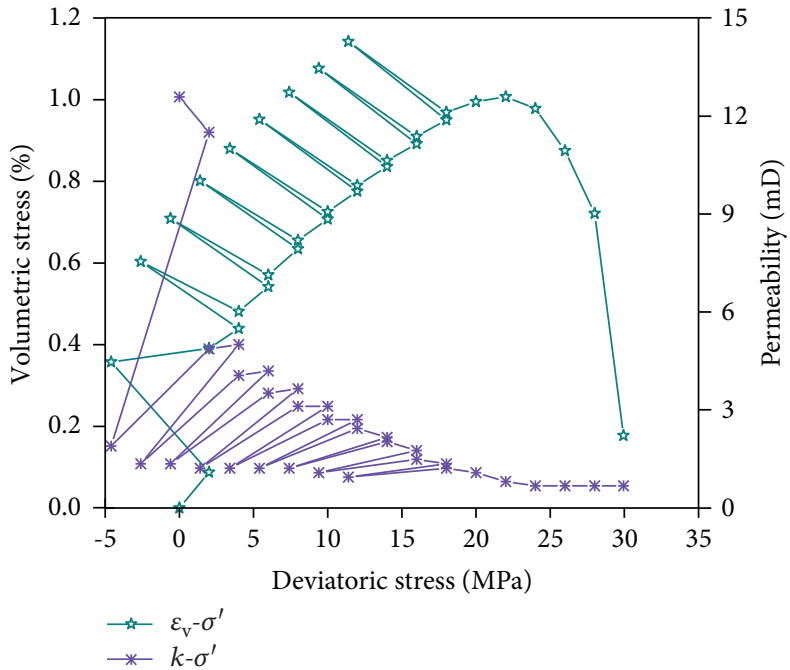

(a)

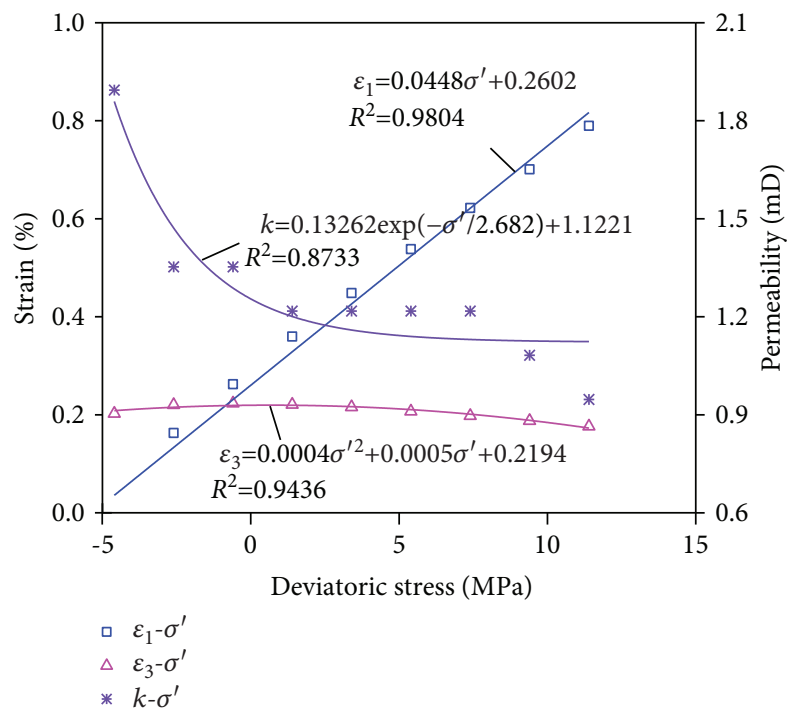

(c)

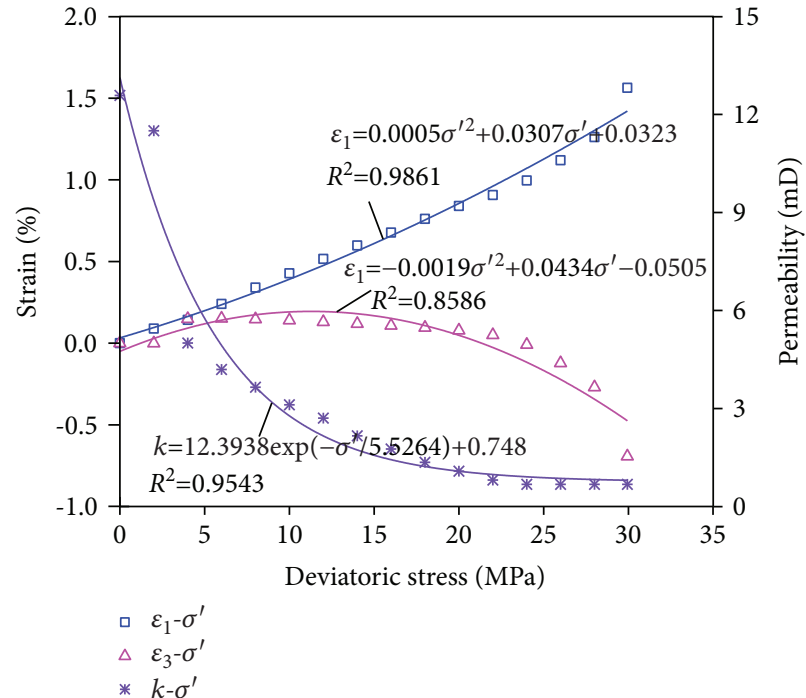

(b)

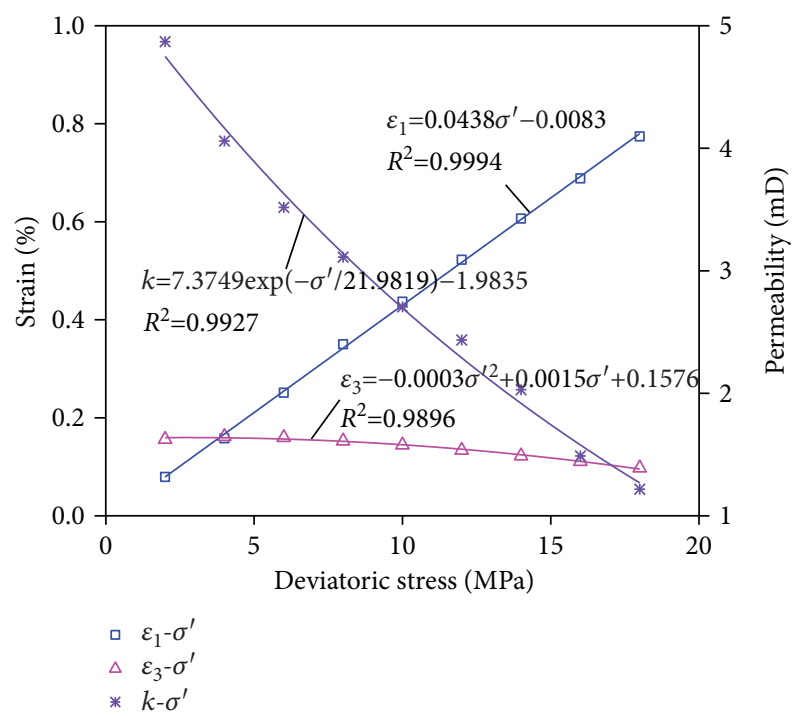

(d)

Figure 4: Strain-deviatoric stress-permeability curves of sample $\# j_{2}$ at different stress levels. (a) Volumetric strain-deviatoric stresspermeability curves; (b) maintain $2 \mathrm{MPa}$ confining pressure, load axial stress ( $2 \mathrm{MPa} \rightarrow 4 \mathrm{MPa} \rightarrow \cdots 20 \mathrm{MPa}$ ) at stage; (c) maintain $8.6 \mathrm{MPa}$ confining pressure, axial stress is $4 \mathrm{MPa}, 6 \mathrm{MPa}, \ldots, 20 \mathrm{MPa}$, respectively; (d) axial stress levels of $4 \mathrm{MPa}, 6 \mathrm{MPa}, \ldots, 20 \mathrm{MPa}$, respectively, unload confining pressure to $2 \mathrm{MPa}$.

rate-axial stress curves and maximum permeability damage rate-axial stress curves of specimens under different axial stresses are shown in Figure 6.

The permeability damage rate-axial stress-maximum permeability damage rate curves of sample $\# j_{1}$ under different axial pressure levels are shown in Figure 6(a). The results show that $d_{k}$ is greatest when axial stress is $4 \mathrm{MPa}$, which indicates that the recovery rate of permeability is the worst after load and unload confining stress under $4 \mathrm{MPa}$ axial stress, and recovery rate is $44.06 \%$. As the axial stress level increases, $d_{k}$ decreases gradually. When the axial stress is $10 \mathrm{MPa}, d_{k}$ has the minimum value and then changes in a stable fluctuation. It shows that the permeability recovery degree of sample $\# j_{1}$ increases gradually with the axial stress level increase, and the recovery degree of permeability tends to be stable when the axial pressure is higher than the stress level of $10 \mathrm{MPa}$. $d_{\max }$ first decreases rapidly and then increases slowly with the increase of the axial stress level, and $d_{\max }$ has the maximum value when axial pressure is $4 \mathrm{MPa}$, which indicates that the permeability reduction degree is the greatest when axial pressure is $4 \mathrm{MPa}$ after load and unload confining pressure. $d_{\max }$ has the minimum value when axial stress is $8 \mathrm{MPa}$, which indicates that the permeability reduction degree is the smallest when the axial stress is $8 \mathrm{MPa}$. With the axial stress level increase, the permeability reduction degree increases gradually, and 


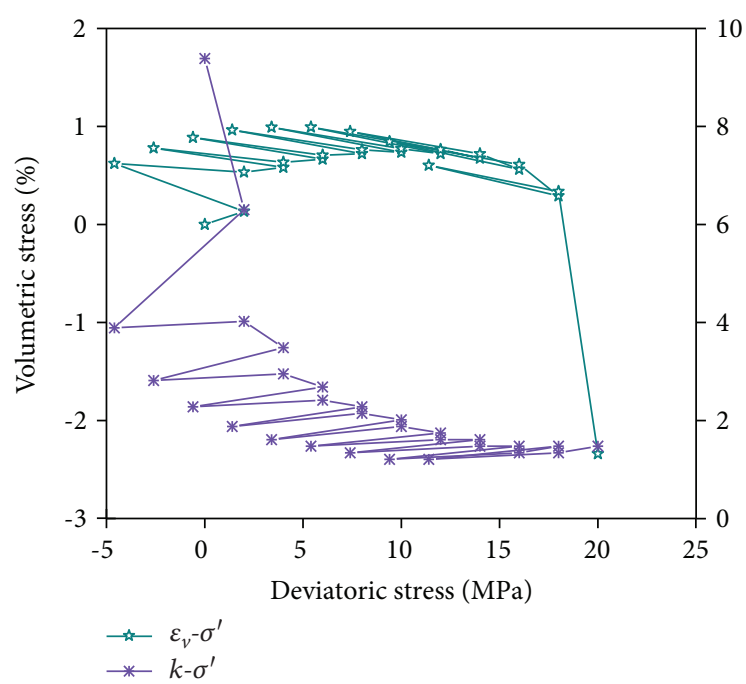

(a)

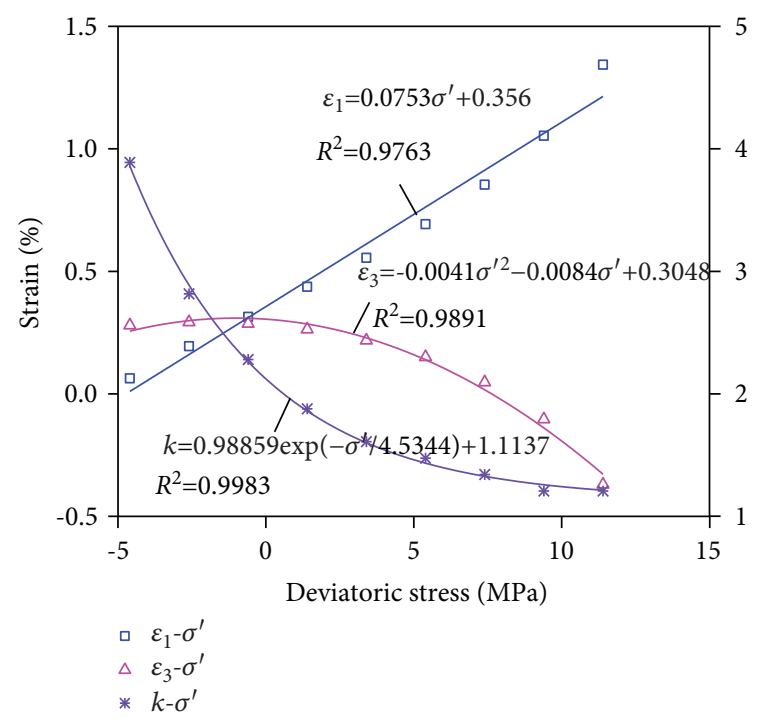

(c)

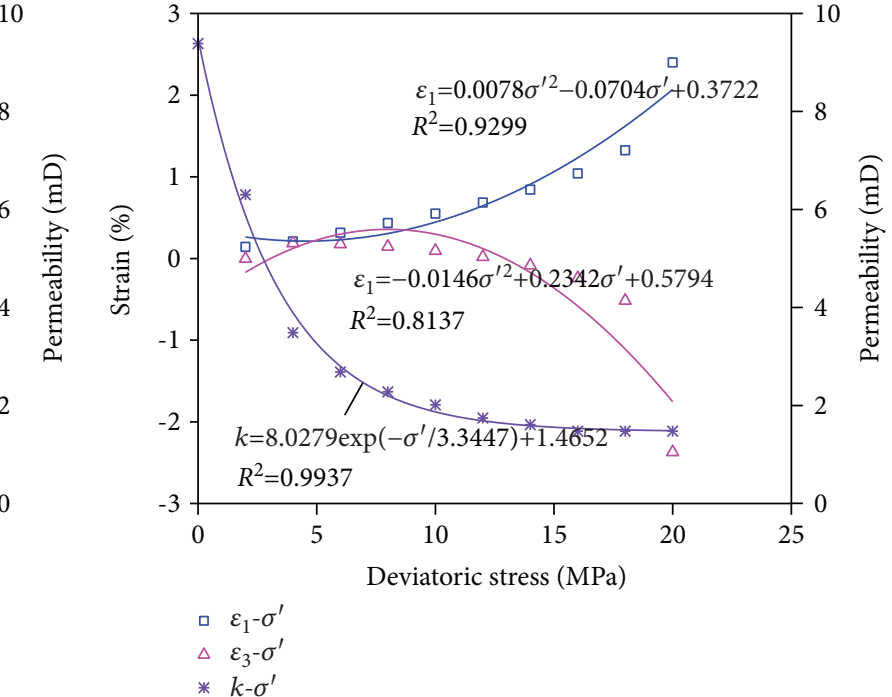

(b)

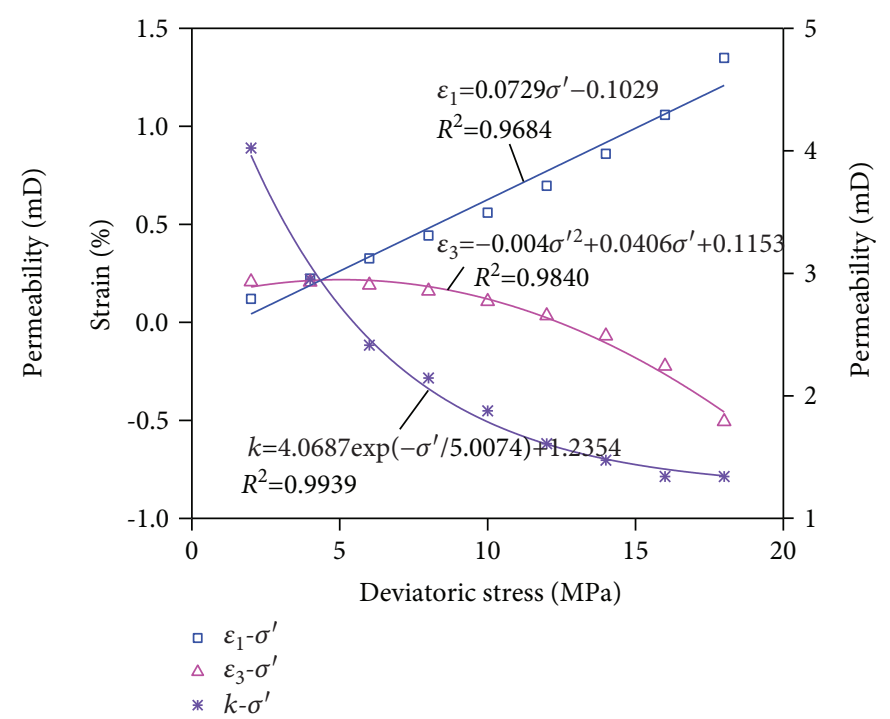

(d)

Figure 5: Strain-deviatoric stress-permeability curves of sample $\# j_{3}$ at different stress levels. (a) Volumetric strain-deviatoric stresspermeability curves; (b) maintain $2 \mathrm{MPa}$ confining pressure, load axial stress $(2 \mathrm{MPa} \rightarrow 4 \mathrm{MPa} \rightarrow \cdots 20 \mathrm{MPa})$ at stage; (c) maintain $8.6 \mathrm{MPa}$ confining pressure, axial stress is $4 \mathrm{MPa}, 6 \mathrm{MPa}, \ldots, 20 \mathrm{MPa}$, respectively; (d) axial stress levels of $4 \mathrm{MPa}, 6 \mathrm{MPa}, \ldots, 20 \mathrm{MPa}$, respectively, unload confining pressure to $2 \mathrm{MPa}$.

the permeability reduction degree reaches the maximum at the axial stress level of $20 \mathrm{MPa}$ but is lower than that at the initial loading stage.

The permeability damage rate-axial pressure-maximum permeability damage rate curves of specimen $\# j_{2}$ under different axial pressure levels are shown in Figure 6(b). We know that $d_{k}$ gradually decreases, and $d_{k}$ has the minimum value at axial stress of $16 \mathrm{MPa}$ after load and unload confining stress; subsequently, as the axial stress level continue to increase, $d_{k}$ increases first and then decreases. $d_{k}$ has the maximum value when the axial stress is $4 \mathrm{MPa}$, which indicates that the recovery rate of permeability is the worst after load and unload confining stress under axial stress of $4 \mathrm{MPa}$, and the recovery rate is $42.35 \%$. When axial stress is loaded from a $4 \mathrm{MPa}$ to $6 \mathrm{MPa}$ stress level, the reduction degree of $d_{k}$ is the greatest after load and unload confining stress; the recovery degree of permeability increases rapidly. With the axial stress level increase, the recovery degree of permeability increases slowly and reaches the maximum value when the axial stress is $16 \mathrm{MPa}$, then the recovery degree of permeability first decreases and then increases. While $d_{\max }$ decreases gradually, $d_{\max }$ is almost linear with the axial stress, indicating that the reduction degree of permeability gradually decreases as the axial stress level increases.

The permeability damage rate-axial pressure-maximum permeability damage rate curves of specimen $\# j_{3}$ under different axial stress levels are shown in Figure 6(c). We know 


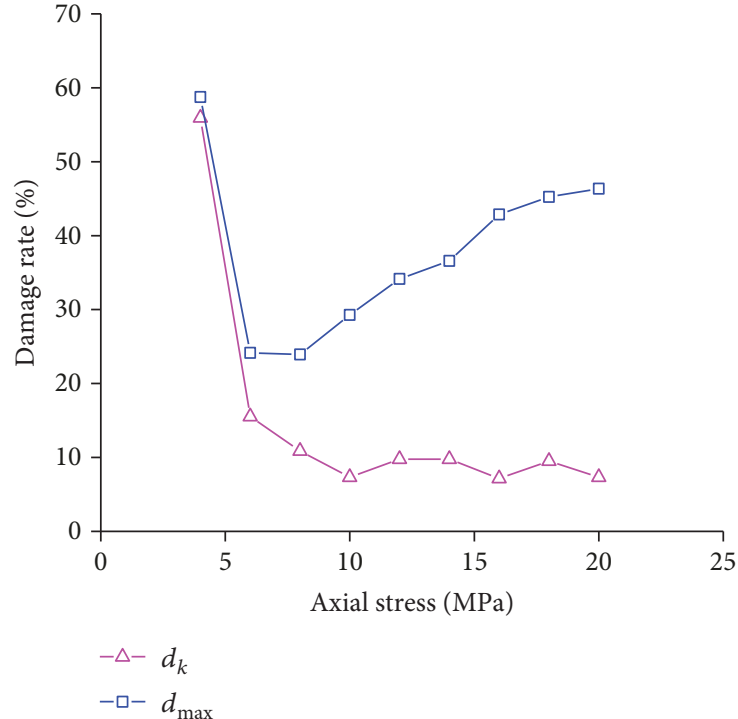

(a) Sample \# $j_{1}$

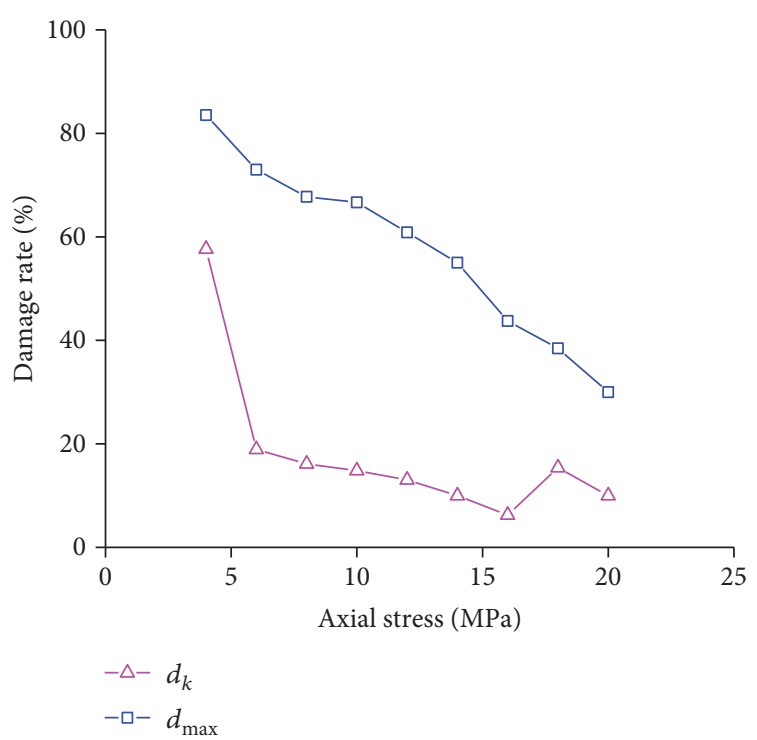

(b) Sample \#j

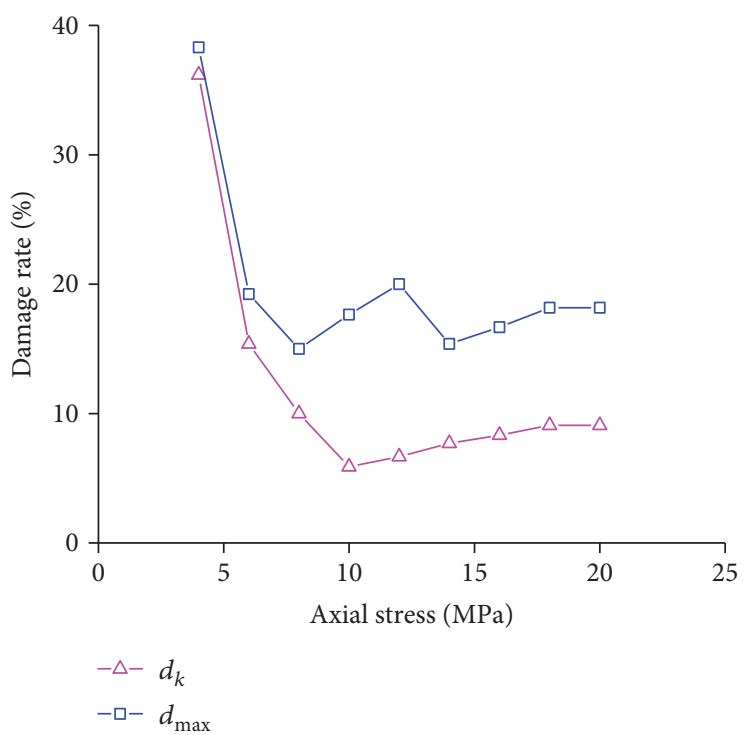

(c) Sample \#j $j_{3}$

FIgURE 6: Permeability damage rate-axial pressure-maximum permeability damage rate curves of samples during the process of load and unload confining pressure.

that as the axial stress level increases, $d_{k}$ gradually decreases, and $d_{k}$ has the minimum value at the axial pressure of $10 \mathrm{MPa}$. Subsequently, as the increase of the axial stress level continues, $d_{k}$ increases gradually, which indicates that the recovery rate of permeability is the worst after load and unload confining stress under axial stress of $4 \mathrm{MPa}$, and the recovery rate is $63.83 \%$. The recovery degree of permeability increases gradually and reaches the maximum value when the axial stress is $10 \mathrm{MPa}$, then the permeability recovery degree gradually decreases. $d_{\max }$ of the sample decreases first, then increases, decreases, and increases the fluctuation of the volatility with the increase of the axial stress level. $d_{\max }$ is $38.3 \%$ under axial stress of $4 \mathrm{MPa}$, which indicates that the reduction degree of permeability has the maximum value at axial stress of $4 \mathrm{MPa}$, and the reduction degree has minimum value at axial stress of $8 \mathrm{MPa}$. When the axial pressure reaches the stress level of $18 \mathrm{MPa}$, the reduction degree of the permeability tends to be stable.

Since the permeability of the sample reflects the change of the effective porosity inside the sample, the increase of the permeability reflects the increase of the porosity, and the decrease of the permeability reflects the decrease of the porosity. Therefore, in the load and unload test process, the permeability of the sample has the same change law as the effective porosity. The damage degree of permeability is also reflected in the porosity. After one time load and unload confining stress, the porosity of the sample 
is also damaged, and the damage rate is equal to $d_{k}$. The sample showed secondary compaction, which is also the reason why the permeability of the sample could not be restored to the initial permeability in the unload confining pressure process under low axial pressure.

\subsection{Expansion Rate of Volumetric Strain of Gas-Containing} Rock Samples. Under the condition of constant axial pressure, the deviatoric stress-volume strain curves of the specimens do not coincide during load and unload confining stress; the volumetric strain is lower than the unload confining pressure process. That is, after load and unload confining stress, the volume of specimen is subject to a certain degree of expansion and deformation. Therefore, the volume expansion rate and the maximum volume expansion rate of the rock sample can be used to evaluate the expansion degree and the increased amplitude of the rock sample volume. The larger the volume expansion rate of the sample is, the greater the expansion degree of the sample's volume will be; the larger the maximum volume expansion rate is, the larger the increased amplitude of the sample's volume will be.

The volume expansion rate $D_{\varepsilon_{\mathrm{v}}}$ can be calculated according to formula (4), and the maximum volume expansion rate $D_{\max }$ can be calculated according to formula (5):

$$
\begin{gathered}
D_{\varepsilon_{v}}=\frac{\varepsilon_{v_{1}}-\varepsilon_{v_{0}}}{\varepsilon_{v_{0}}} \times 100 \%, \\
D_{\max }=\frac{\varepsilon_{v_{\max }}-\varepsilon_{v_{0}}}{\varepsilon_{v_{0}}} \times 100 \%,
\end{gathered}
$$

where $\varepsilon_{v_{1}}$ is the volumetric strain at the last stress point of unloading confining stress, $\varepsilon_{v_{0}}$ is the volumetric strain at the first stress point of load confining stress, and $\varepsilon_{v_{\max }}$ is the volumetric strain measured at the maximum stress point.

According to equations (4) and (5), the variation curves of the volume expansion rate and maximum volume expansion rate under different axial stress levels during load and unload confining stress are shown in Figure 7.

The volume expansion rate-axial stress-maximum volume expansion rate variation curves of sample $\# j_{1}$ during the load and unload confining pressure process are shown in Figure 7(a). It can be seen that the volume expansion rate is about $422.05 \%$ at axial stress of $4 \mathrm{MPa}$ after load and unload confining stress, which indicates that the volume expansion degree of the sample is the largest when the axial stress is $4 \mathrm{MPa}$. The volume expansion rate decreases rapidly to $8.6 \%$ when the axial stress reaches $6 \mathrm{MPa}$ and then decreases slowly as the axial stress level increases. The volume expansion rate tends to decrease when the axial stress reaches $12 \mathrm{MPa}$, that is, the volume expansion degree decreases slowly with the increase of the axial stress level. The maximum volume expansion rate of the specimen has a similar variation with the volume expansion rate. \When the axial stress reaches $6 \mathrm{MPa}$, the maximum volume expansion rate decreases rapidly to
$50.76 \%$, and then, the increasing degree of volumetric strain decreases slowly.

The volume expansion rate-axial stress-maximum volume expansion rate variation curves of sample $\#_{2}$ in the load and unload confining pressure process are shown in Figure $7(\mathrm{~b})$. It can be seen that the volume expansion rate is about $347.27 \%$ at axial pressure of $4 \mathrm{MPa}$, which indicates that the volume expansion degree of the sample is the largest when the axial stress is $4 \mathrm{MPa}$. The volume expansion rate decreases rapidly to $9.6 \%$ when the axial stress reaches $6 \mathrm{MPa}$ and then decreases slowly and tends to be stable as the axial stress level increases. That is, as the axial stress level increases, the volume expansion degree of samples decreases slowly and tends to be stable. The maximum volume expansion rate of the specimen is about $309.12 \%$ after load and unload confining stress at axial stress of $4 \mathrm{MPa}$, which indicates that the volumetric strain is the largest when the axial stress is $4 \mathrm{MPa}$. The maximum volume expansion rate of the specimen decreases rapidly to $37.36 \%$ when the axial stress level reaches $6 \mathrm{MPa}$, then the volumetric strain increases slowly.

The volume expansion rate-axial stress-maximum volume expansion rate variation curves of sample $\# j_{3}$ in the load and unload confining stress process are shown in Figure 7(c). It can be seen that the volume expansion rate is about $297.06 \%$ at axial stress of $4 \mathrm{MPa}$, which indicates that the volume expansion degree of the sample is the largest when the axial stress is $4 \mathrm{MPa}$. The volume expansion rate decreases rapidly to $8.79 \%$ when the axial stress reaches $6 \mathrm{MPa}$ and then increases slowly as the axial stress level increases. That is, the volume expansion degree of the specimen is the smallest at the axial stress level of $6 \mathrm{MPa}$ and then increases slowly. The maximum volume expansion rate of the specimen is about $309.12 \%$ after load and unload confining stress at axial stress of $4 \mathrm{MPa}$, which indicates that the increased amplitude of volumetric strain is the largest at axial stress of $4 \mathrm{MPa}$. When the axial stress level reaches $6 \mathrm{MPa}$, the maximum volume expansion rate decreases rapidly to $33.88 \%$ and then increases slowly, and the curvature increases slowly. That is, the increased amplitude of volumetric strain is the lowest when the axial stress is $6 \mathrm{MPa}$ and then increases gradually as the axial stress level continues to increase.

Since the volumetric strain of the sample reflects the change of the effective porosity inside the sample during the test, the increase of the volumetric strain reflects the increase of the internal porosity of the sample, and the decrease of the volumetric strain reflects the decrease of the internal porosity of the sample. Therefore, in the load and unload test, the volumetric strain of the specimen has the same variation law as the effective porosity, and the volume expansion degree of the sample is also reflected in porosity. After one time load and unload confining stress, the porosity of the specimen is also damaged, and the damage rate is equal to the volume expansion rate. The secondary compaction occurs inside the sample during the test, which is also the reason why the volumetric strain of the specimen cannot be restored to the initial 


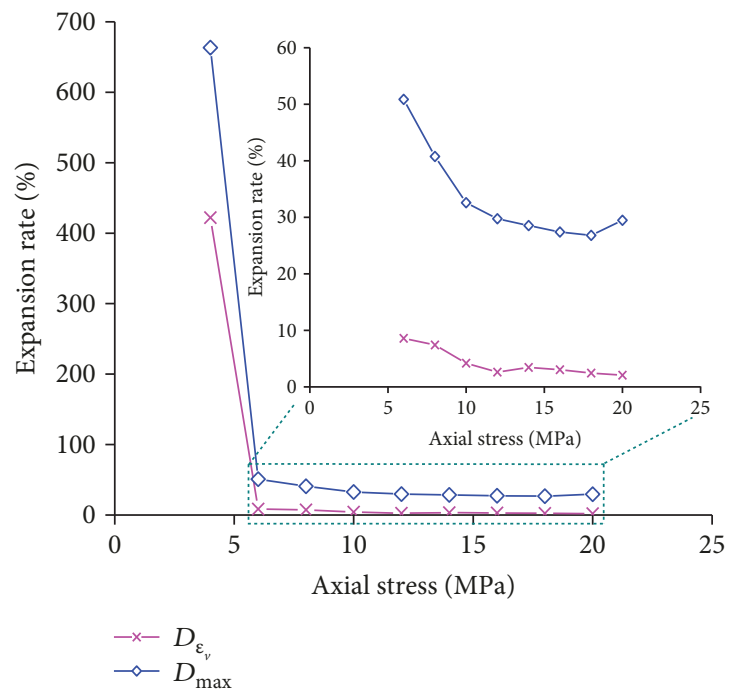

(a) Sample $\# j_{1}$

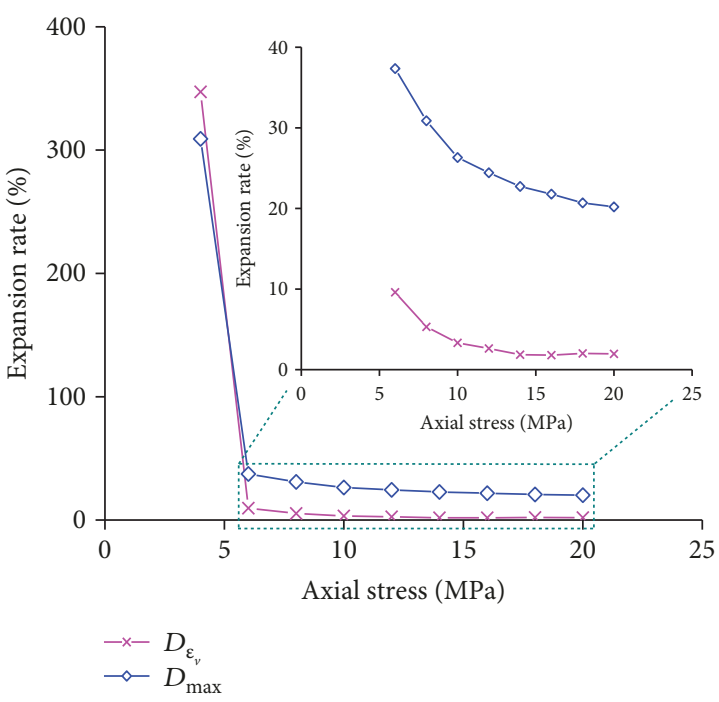

(b) Sample $\# j_{2}$

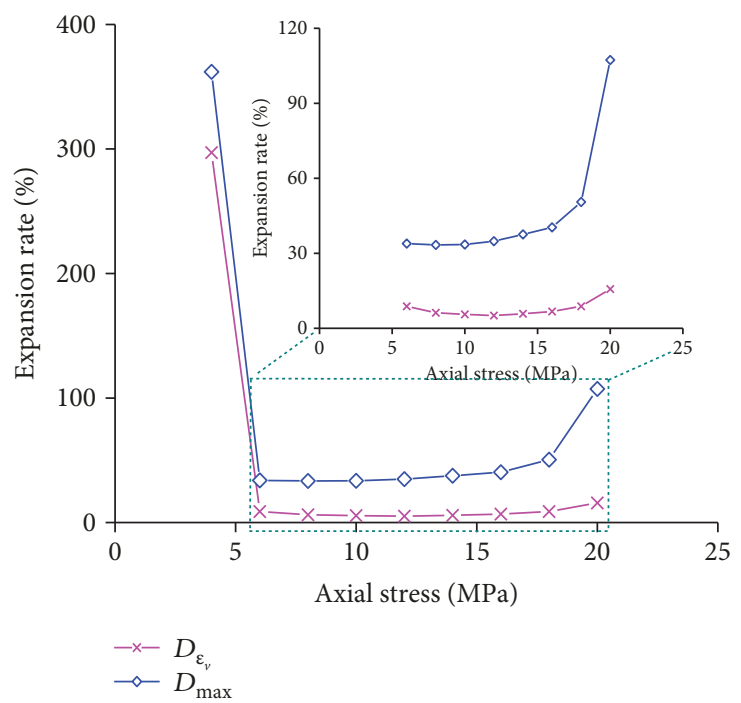

(c) Sample $\# j_{3}$

FIGURE 7: Volume expansion rate-axial stress-maximum volume expansion rate variation curves of samples during the process of load and unload confining pressure.

volumetric strain in the unload confining stress process under low axial pressure.

\section{Discussion}

In the process of coal seam mining, the coal and rock in front of the working face undergo the loading and unloading process, which can be divided into stress reduction area, stress increase area, and original stress area. The process of confining pressure loading can simulate the permeability change law of coal and rock in the stress increase area. During the loading confining pressure process, the axial strain of the specimen is almost constant, and the radial strain increases in the positive direction, which results in the increase of the volumetric strain. Correspondingly, after loading the confining pressure, the increased range of volumetric strain can be expressed by the maximum volumetric expansion rate. In the process of loading confining pressure, the microvoids and cracks in the sample are gradually closed, which makes it more difficult for gas to pass through the sample and reduces the permeability of the sample. Correspondingly, after loading the confining pressure, the decreased range of permeability can be expressed by the maximum permeability damage rate.

The process of unloading confining pressure of the sample can simulate the permeability change law of coal and rock in the stress reduction zone. During the process of unloading confining pressure, the axial strain of the sample is almost constant, the radial direction appears expansion deformed, the radial strain decreases, and the volumetric strain of the 
specimen decreases. Correspondingly, the volume expansion degree of the specimen after one loading and unloading confining pressure can be expressed by the volume expansion rate. In the process of unloading confining pressure, the microvoids and cracks in the sample gradually open, which reduces the difficulty of gas passing through the sample and increases the permeability of the sample. Correspondingly, the recovery degree of the permeability of the sample after one loading and unloading confining pressure can be expressed by the permeability damage rate.

\section{Conclusion}

(1) The relationship between radial strain and deviatoric stress satisfied the quadratic polynomial function, and the relationship between permeability and deviatoric stress satisfied the exponential function under different axial stress levels

(2) In the staged load axial stress process, the axial straindeviatoric curves of specimens conform to the quadratic polynomial function. The axial straindeviatoric curves of specimens conform to the linear function when the confining pressure is $8.6 \mathrm{MPa}$ or 2.0 $\mathrm{MPa}$ at different axial stress levels

(3) We used the permeability damage rate and maximum permeability damage rate to evaluate the recovery degree and the reduction extent of permeability

(4) We used the volume expansion ratio and the maximum volume expansion ratio to evaluate the expansion degree and increase extent of rock samples' volume

\section{Data Availability}

All included experimental data are absolutely reliable, the datasets supporting this article have been uploaded as part of the electronic supplementary material, and the raw data is in Excel format.

\section{Conflicts of Interest}

The authors declare that they have no competing interests.

\section{Authors' Contributions}

Dongming Zhang and Yushun Yang conceived and designed the experiments; Yushun Yang and Shujian Li performed the experiments and analyzed the data; Yushun Yang wrote the paper. All authors gave final approval for publication.

\section{Acknowledgments}

The authors acknowledge the National Science and Technology Major Project of China (2016ZX05045-004).

\section{Supplementary Materials}

The original data are the test data monitored by three rock samples during the test. (Supplementary Materials)

\section{References}

[1] H. M. Zhang, "Experimental on gaseous seepage properties of sandstone in complete stress-strain process," Journal of China Coal Society, vol. 34, no. 9, pp. 1063-1066, 2009.

[2] S. Ghabezloo, J. Sulem, S. Guédon, and F. Martineau, "Effective stress law for the permeability of a limestone," International Journal of Rock Mechanics and Mining Sciences, vol. 46, no. 2, pp. 297-306, 2009.

[3] D. Ma, X. X. Miao, Z. Q. Chen, and X. B. Mao, "Experimental investigation of seepage properties of fractured rocks under different confining pressures," Rock Mechanics and Rock Engineering, vol. 46, no. 5, pp. 1135-1144, 2013.

[4] W. Wei, W. Y. Xu, R. B. Wang, Y. J. Cao, H. L. Wang, and S. R. Feng, "Permeability of dense rock under triaxial compression," Chinese Journal of Rock Mechanics and Engineering, vol. 34, no. 1, pp. 40-47, 2015.

[5] W. Wei, Z. Zheng, R. B. Wang, H. L. Wang, and W. Y. Xu, "Experimental study of permeability properties of granitic gneiss under different stress paths," Chinese Journal of Rock Mechanics and Engineering, vol. 35, no. 2, pp. 260-267, 2016.

[6] T. Jiang, J. F. Shao, W. Y. Xu, and C. B. Zhou, "Experimental investigation and micromechanical analysis of damage and permeability variation in brittle rocks," International Journal of Rock Mechanics and Mining Sciences, vol. 47, no. 5, pp. 703-713, 2010.

[7] R. Zhang, Z. Jiang, Q. Sun, and S. Zhu, "The relationship between the deformation mechanism and permeability on brittle rock," Natural Hazards, vol. 66, no. 2, pp. 1179-1187, 2013.

[8] L. Wang, J. F. Liu, J. L. Pei, H. N. Xu, and Y. Bian, "Mechanical and permeability characteristics of rock under hydromechanical coupling conditions," Environmental Earth Sciences, vol. 73, no. 10, pp. 5987-5996, 2015.

[9] Y. Zhao, Y. Wang, W. Wang, L. Tang, Q. Liu, and G. Cheng, "Modeling of rheological fracture behavior of rock cracks subjected to hydraulic pressure and far field stresses," Theoretical and Applied Fracture Mechanics, vol. 101, pp. 59-66, 2019.

[10] W. Xu, R. Wang, W. Wang, Z. Zhang, J. Zhang, and W. Wang, "Creep properties and permeability evolution in triaxial rheological tests of hard rock in dam foundation," Journal of Central South University, vol. 19, no. 1, pp. 252-261, 2012.

[11] Z. Liu, J. Shao, S. Xie, and J. Secq, "Gas permeability evolution of clayey rocks in process of compressive creep test," Materials Letters, vol. 139, pp. 422-425, 2015.

[12] Z. B. Jiang, A. N. Jiang, H. Li, and S. Y. Wang, "Creep-seepage coupling laws of quartzite under cyclic loading-unloading conditions," Chinese Journal of Geotechnical Engineering, vol. 39, no. 10, pp. 1832-1841, 2017.

[13] Q. Kong, H. L. Wang, and W. Y. Xu, "Experimental study on permeability and porosity evolution of sandstone under cyclic loading and unloading," Chinese Journal of Geotechnical Engineering, vol. 37, no. 10, pp. 1893-1900, 2015. 
[14] C. H. Liang, L. I. Jianfeng, W. A. Chunping, L. I. Jian, S. U. Rui, and W. A. Ju, "Investigation on damage evolution characteristic of granite under compressive stress condition and its impact on permeability," Chinese Journal of Rock Mechanics and Engineering, vol. 33, no. 2, pp. 287-295, 2014.

[15] Y. Zhao, Y. Wang, W. Wang, W. Wan, and J. Tang, "Modeling of non-linear rheological behavior of hard rock using triaxial rheological experiment," International Journal of Rock Mechanics and Mining Sciences, vol. 93, pp. 6675, 2017.

[16] L. Wei, Q. Yue-ping, Z. Miao-miao, W. Cui-xia, and W. Ya-ru, "Test study on permeability properties of the sandstone specimen under triaxial stress condition," Procedia Engineering, vol. 26, pp. 173-178, 2011.

[17] D. M. Zhang, B. B. Zheng, X. M. Zhang, X. H. Qi, and X. Bai, "Experimental study on the deformation characteristics and permeability laws of gas infiltrated sandstone under unloading confining pressure condition," Rock and Soil Mechanics, vol. 38, no. 12, pp. 3475-3490, 2017.

[18] D. M. Zhang, B. B. Zheng, G. Z. Yin, X. M. Zhang, and Y. S. Yang, "Mechanics and permeability characteristics of steep seam roof sandstone under disturbance stress," Journal of China Coal Society, vol. 42, no. z1, pp. 128-137, 2017.

[19] F. Huang and B. Hu, "Macro/microbehavior of shale rock under the dynamic impingement of a high-pressure supercritical carbon dioxide jet," RSC Advances, vol. 8, no. 66, pp. 38065-38074, 2018.

[20] L. G. Wang, Y. Zhang, X. F. Liu, and Q. Chen, "Experimental research on seepage characteristics of sandstone with single fracture," Bulletin of the Chinese Ceramic Society, vol. 37, no. 5, pp. 1804-1811, 2018.

[21] F. Huang, S. Li, Y. Zhao, and Y. Liu, "Study on lateral jetting range during an arc-curved jet impacting nonplanar solid surfaces," Journal of Fluids Engineering, vol. 140, no. 10, pp. 101201-101211, 2018.

[22] L. He, Q. Yin, and H. Jing, "Laboratory investigation of granite permeability after high-temperature exposure," Processes, vol. 6, no. 4, p. 36, 2018.

[23] F. F. Menezes, "Anisotropy of volume change and permeability evolution of hard sandstones under triaxial stress conditions," Journal of Petroleum Science and Engineering, vol. 174, pp. 921-939, 2019.

[24] Y. Zhao, L. Zhang, W. Wang, J. Tang, H. Lin, and W. Wan, "Transient pulse test and morphological analysis of single rock fractures," International Journal of Rock Mechanics and Mining Sciences, vol. 91, pp. 139-154, 2017.

[25] P. F. Shan and X. P. Lai, "Numerical simulation of the fluid-solid coupling process during the failure of a fractured coal-rock mass based on the regional geostress," Transport in Porous Media, vol. 124, no. 3, pp. 1061-1079, 2018.

[26] M. X. Jing and X. L. Yuan, "Experimental research on core stress sensitivity of carbonate rock," Natural Gas Industry, vol. 22, no. z1, pp. 114-117, 2002.

[27] D. K. Wang, J. P. Wei, and G. Z. Yin, "Investigation on change rule of permeability of coal containing gas under complex stress paths," Chinese Journal of Rock Mechanics \& Engineering, vol. 31, no. 2, pp. 303-310, 2012. 

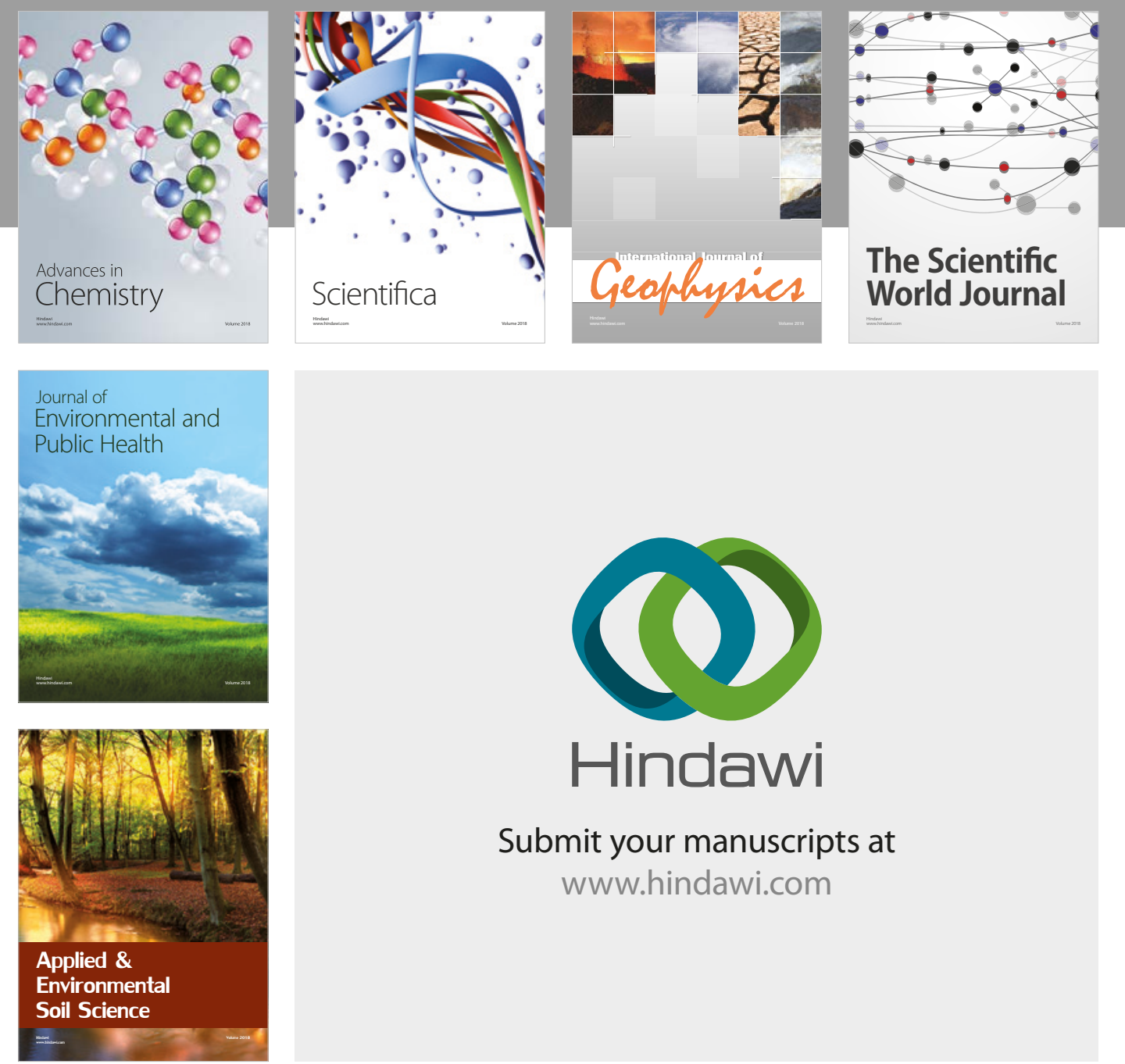

The Scientific

\section{World Journal}
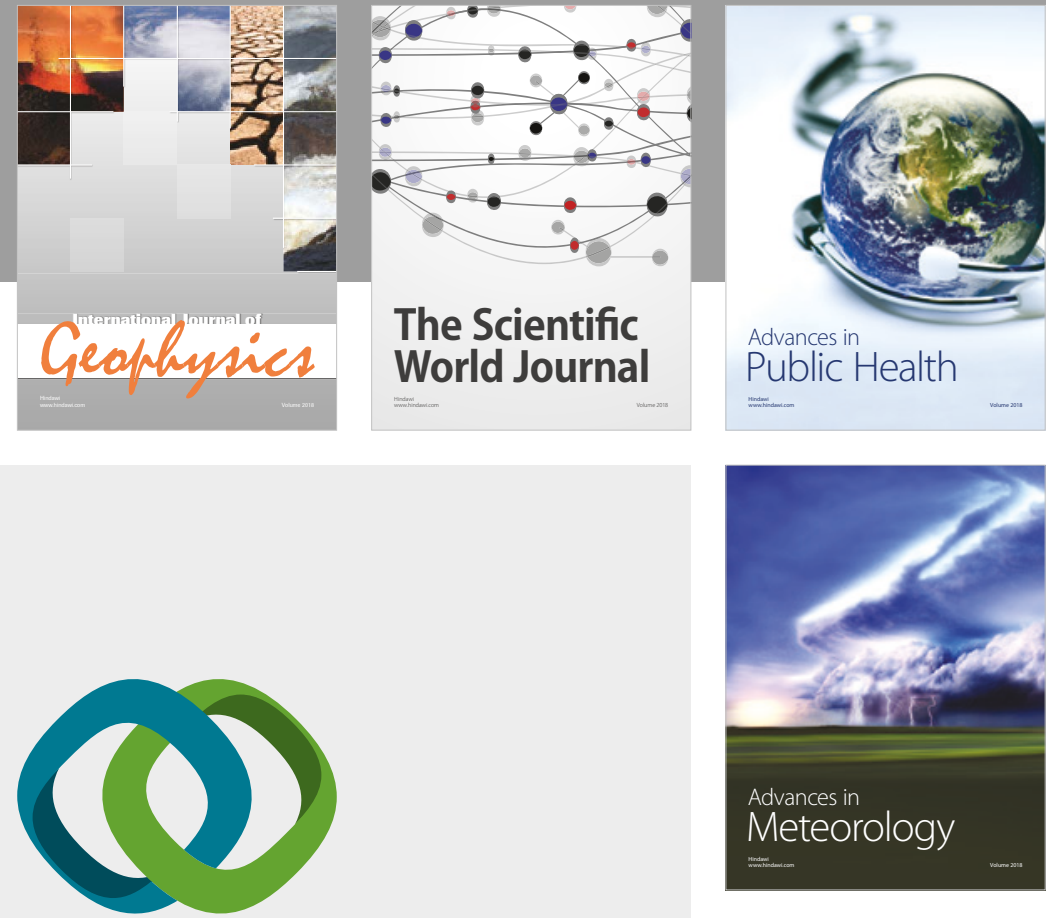

Advan

Public Health

\section{Hindawi}

Submit your manuscripts at

www.hindawi.com
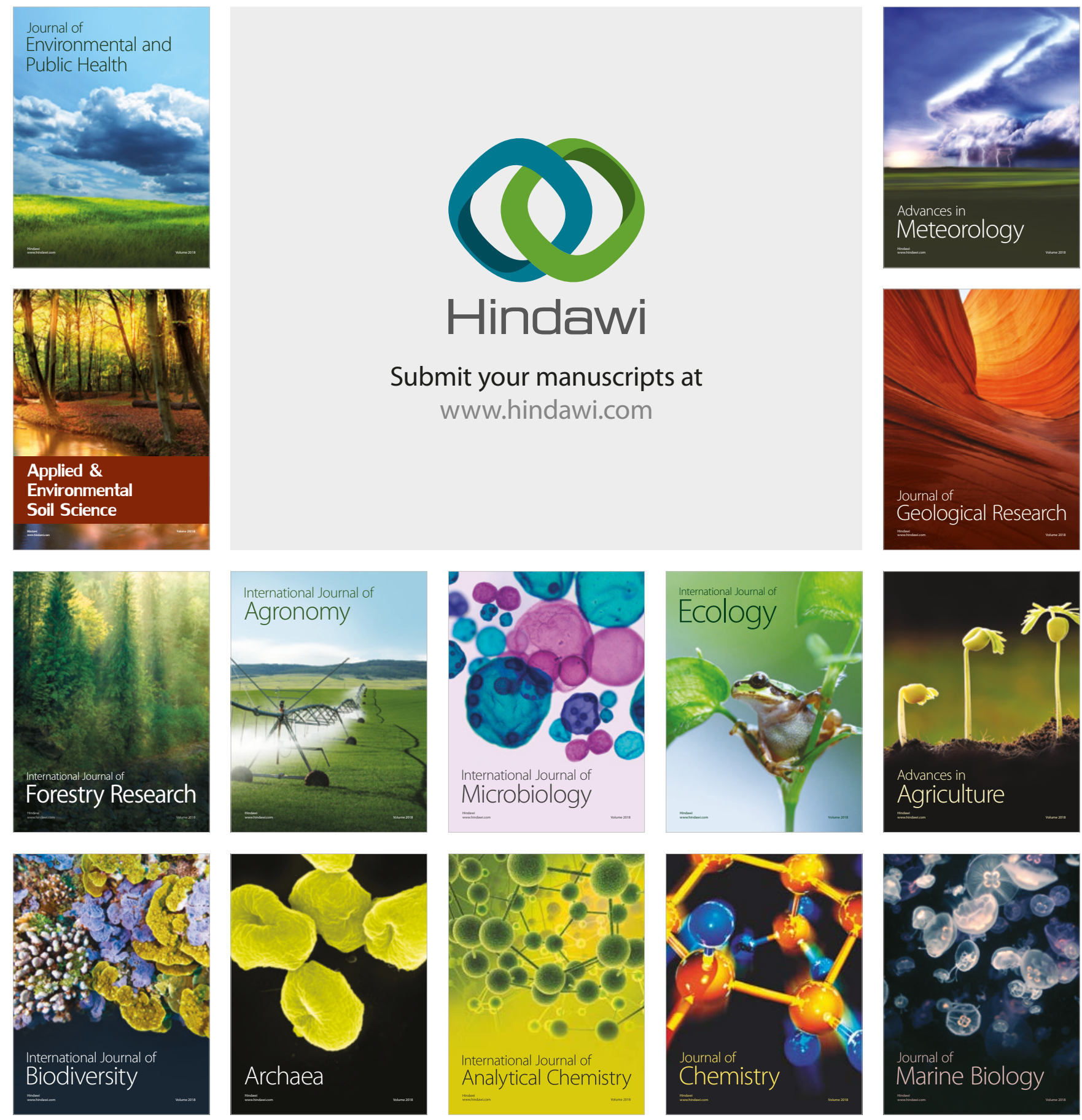